\title{
The Representation of the Syrian Refugees in the Westerners' Comments on Facebook Refugee images in 2015: Corpus-based Multimodal Analysis
}

A research submitted by

Mai Anas Lotfy Mohammad Zahra

An M.A student

Ain Shams University

Faculty of Al-Alsun (Languages)

Department of English Language and Translation

\section{Linguistics Section}

\section{(Summary)}

The study applies the appraisal theory, corpus linguistics, and multimodal critical discourse analysis to identify the positive and negative representation of the Syrian refugees. The researcher collects ten images from Facebook and their comments posted by Europeans, Americans, Australians, and Canadians. The data are collected during 2015, the year in which the Syrian refugee crisis has aggravated, and the flow of the refugees into the western communities has increased. The researcher adopts the appraisal theory of Martin and White (2005) to annotate the attitudinal realizations on UAM CorpusTool 3.0 to highlight the refugees' emotions, behaviour, and conditions. The researcher has used the attitude subsystems: affect, judgement, and appreciation, using the built-in scheme on the software program in addition to other modifications added to get accurate results. The researcher has saved each image comments in a text file which is in turn saved on the software program to be manually annotated. Then the results are automatically retrieved to set a frequency list based on the most representative appraising features displayed by the data. Therefore, the study depends on the quantitative and qualitative analyses. On the visual level, the images are analyzed according to the approach of Machin and Mayr (2012). That is, the multimodal critical 
The Representation of the Syrian Refugees in the Westerners' Comments on

Facebook Refugee images in 2015: Corpus-based Multimodal Analysis

discourse analysis of the images enable the researcher to focus on the Syrian refugees' attributes, settings, clothes, facial expressions, salience, gazes, postures, and their interactional strategies with the viewer. The objective is to identify the refugees' identities and ideologies. Hence, the verbal and visual analyses of the data are combined to explore the representation of the Syrian refugees' thoughts, ethics, feelings, and characteristics.

Keywords: Appraisal Theory - Attitude - Syrian Refugees Multimodal Critical Discourse Analysis - Corpus Linguistics

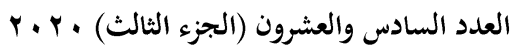

مجلة كلية التربية- جامعة عين شمس 


\section{صورة اللاجئين السوريين في تعليقات الغربيين على صور اللاجئين

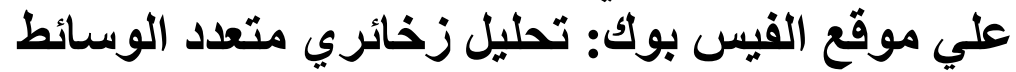

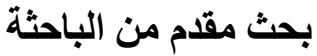

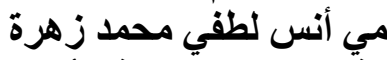

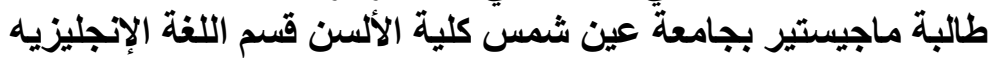 معيدة بدوام جزئي بالأكاديمية البحرية للعطوم والتكنية الالكنولوجيا بالقرية الأكية}

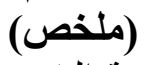

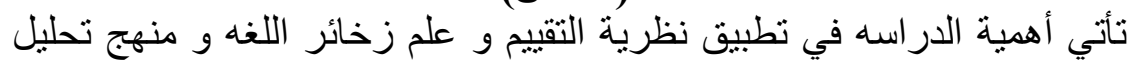

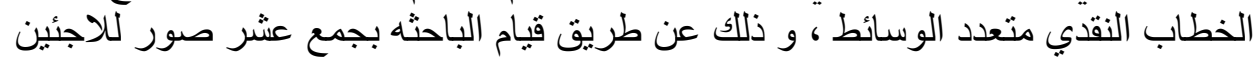

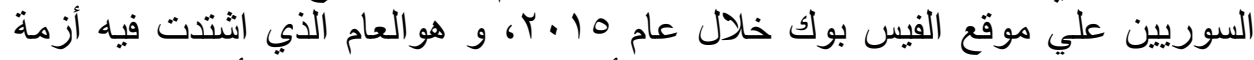

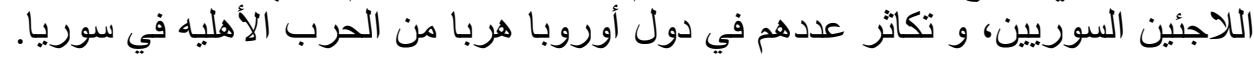

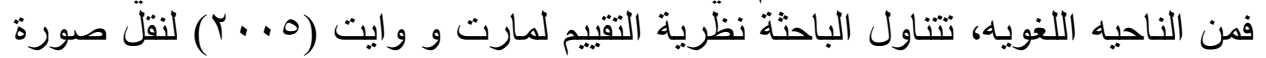

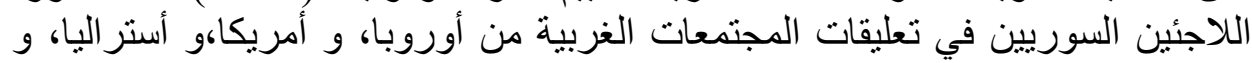

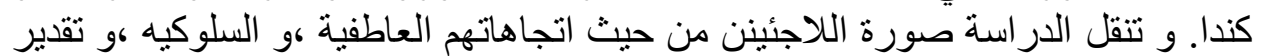

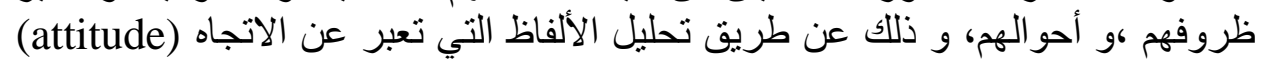

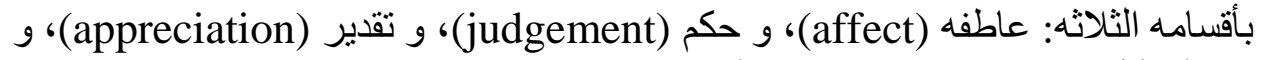

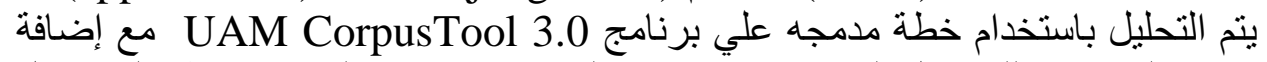

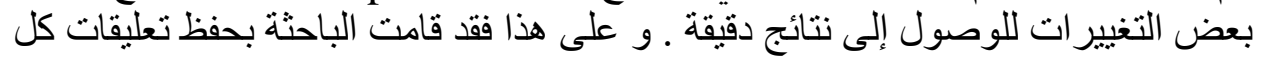

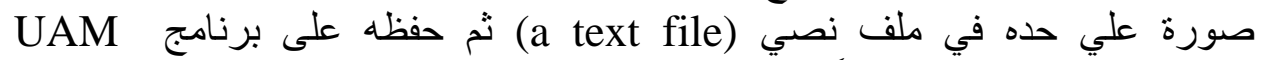
بCorpusTool 3.0

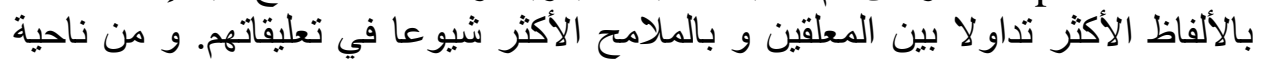

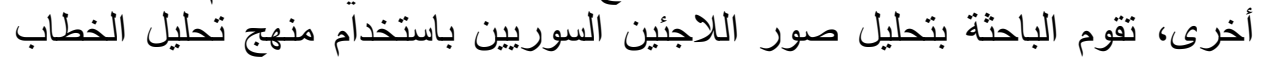

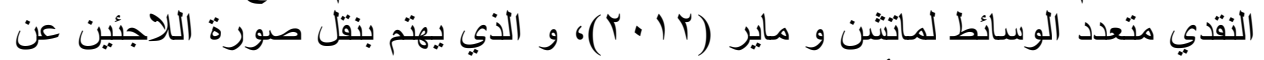

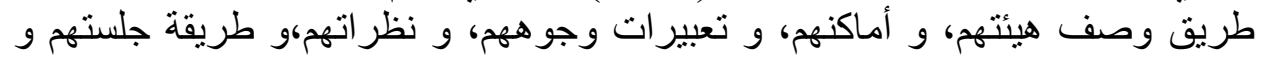

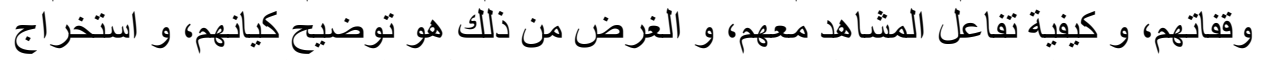

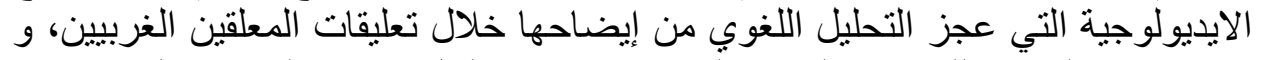

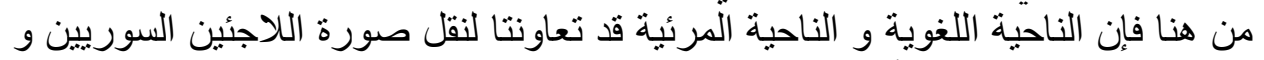

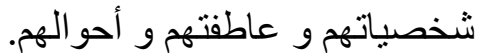
الكلمات المفتاحية: نظرية التقييم - الاتجاه ـ اللاجئين السوريين - تحليل خطاب متعدد الوسائط - علم زخائر اللغنه

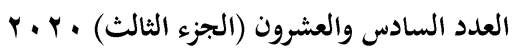


The Representation of the Syrian Refugees in the Westerners' Comments on

Facebook Refugee images in 2015: Corpus-based Multimodal Analysis

\section{The Representation of the Syrian Refugees} in the Westerners' Comments on Facebook Refugee images in 2015: Corpus-based Multimodal Analysis

A research submitted by Mai Anas Lotfy Mohammad Zahra

An M.A student

Ain Shams University

Faculty of Al-Alsun (Languages)

Department of English Language and Translation

\section{Introduction}

\section{Linguistics Section}

\subsection{Context of the study}

The Syrian refugee crisis has witnessed a great attention all over the world since 2011 as one of the repercussions of the Arab Spring revolutions in different Arab countries, including Syria. Then the Syrian status aggravated since the Civil War waged between the supporters of the Syrian President Bashar AL Assad and his opponents in addition to some terrorist groups: the Islamic State. Such attacks lead to the death of 250,000 Syrians in four and a half years of armed conflicts. (Syria: The Story of the Conflict, 2016). Consequently, Syrians decide to refuge to the neighbouring countries and Europe as shown in the image below.

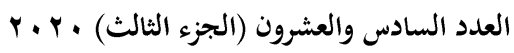

مجلة كلية التربية- جامعة عين شمس 


\section{Mai Anas Lotfy Mohammad Zahra}

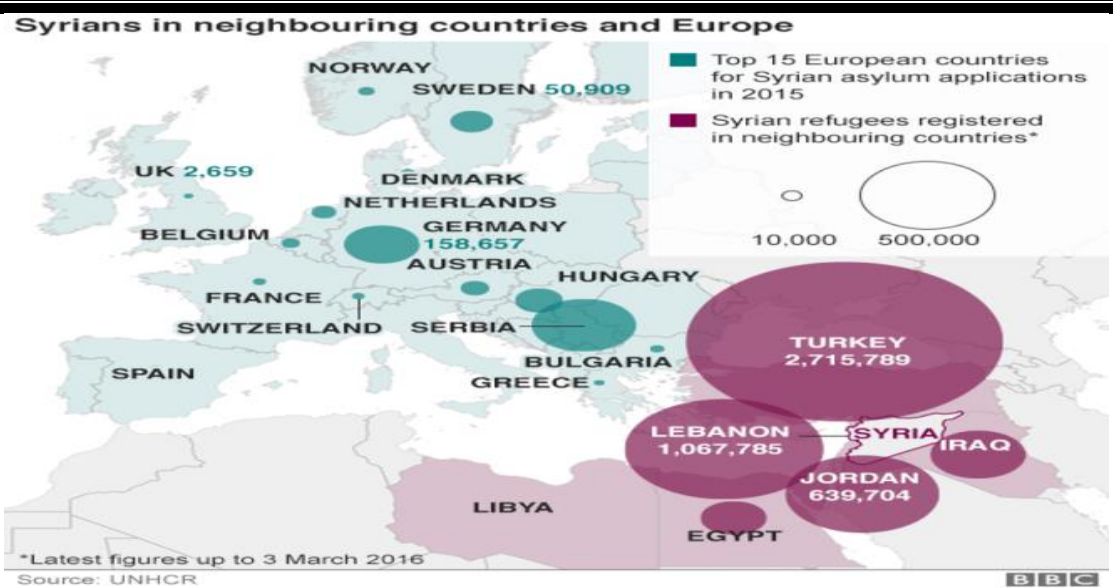

Image (1) Syrians in Neighbouring Countries and Europe (Syrian: The Story of the Conflict, 2016)

The image illustrates that Turkey embraces the largest amount of the Syrian refugees followed by Lebanon and Jordan, whereas a small percentage of Syrians have fled to Iraq and Egypt. On the other hand, Serbia tops the list of the European countries which welcome the refugees, while Germany occupies the second place before Sweden. It is also clear that Bulgaria, the United Kingdom, France, Switzerland, and Greece close their eyes to the Syrian regugees' crisis by receiving only small numbers (Syria: The Story of the Conflict, 2016).

This study tackles the representation of the Syrian refugees' attitude: feelings, behaviour, and conditions from the perspective of the western commentators on Facebook under the appraisal framework (Martin \& White, 2005). In other words, the researcher analyzes the comments of the western commentators, regarding the appraisal subcategory attitude which is further classified into affect, judgement, and appreciation. The attitudinal expressions are manually annotated on UAM CorpusTool before the automatic retrieval of the results. In addition, the researcher adopts the approach of Machin and Mayr (2012) to critically analyze the Syrian refugees' images on Facebook. 
The Representation of the Syrian Refugees in the Westerners' Comments on

Facebook Refugee images in 2015: Corpus-based Multimodal Analysis

\subsection{Objectives of the Study:}

The research performs a corpus-based multimodal analysis of the Syrian refugees' images and westerners' comments on them. In this regard, the study aims to examine the refugees' feelings, identity, and conditions in the western host countries via the perspective of the western commentators. Second, it visualizes the refugees' emotions by describing their appearance and facial expressions besides other semiotic features. Finally, it sets a qualitative and quantitative analyses for the data to critically discuss how the western communities describe the refugees concerning their emotions, behaviour, and circumstances.

\subsection{Research Questions:}

1. How are the Syrian refugees' identity and emotions represented in the westerners' discourse on Facebook?

2. What are the most representative evaluative features describing the Syrian refugees?

3. How does the semiotic analysis of the Syrian refugees' appearance and feelings contribute to the study?

4. How do the refugees' poses and gazes affect the viewers' thoughts and feelings?

\section{Methodology}

\subsection{Data and data collection}

The researcher has collected 10 images of Syrian refugees on Facebook dated to 2015 during which the Syrian refugee crisis was exacerbated. In this sense, the appraising items that show affect, appreciation, and judgement are extracted. The researcher also uses a built-in scheme of Appraisal Theory in UAM CorpusTool software program and adds some modifications to match the analysis needs and achieve accuracy. The following diagram gives an example of the built-in scheme:

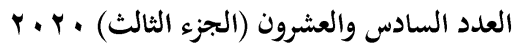

مجلة كلية التربية- جامعة عين شمس 
Mai Anas Lotfy Mohammad Zahra

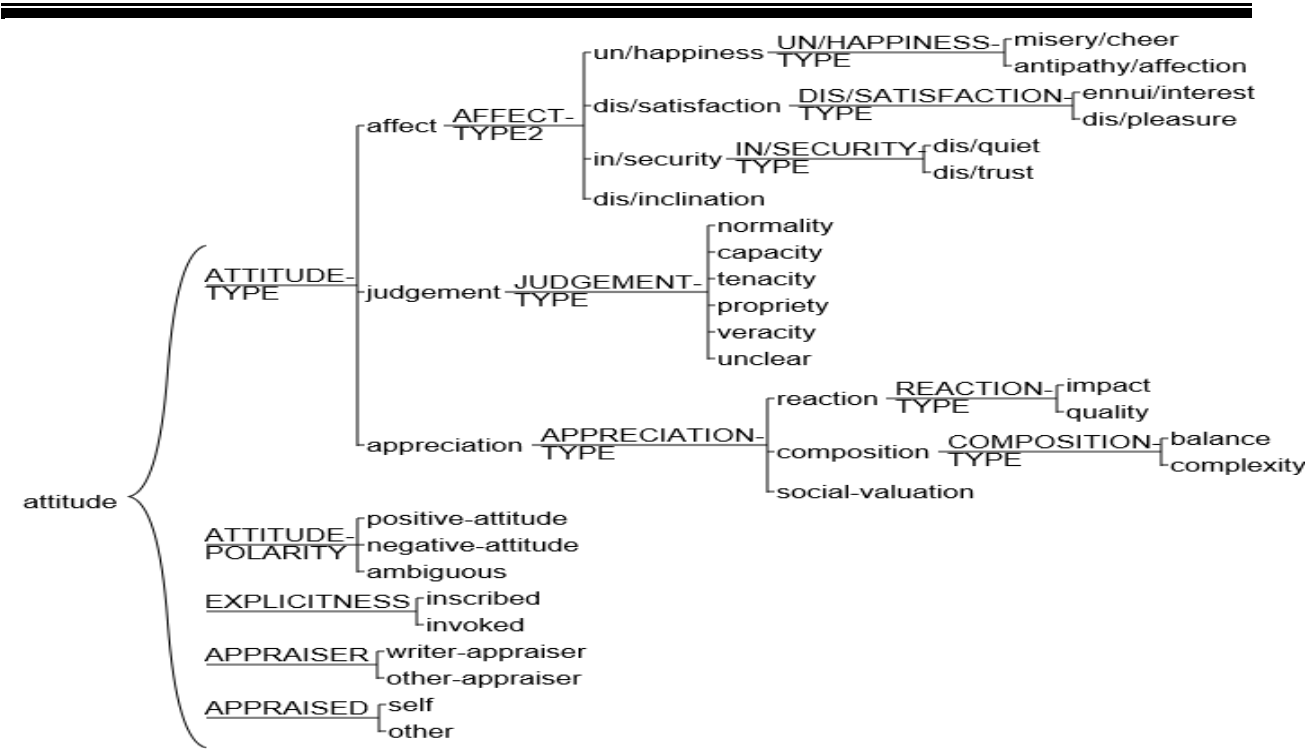

Figure (1) Built-in Scheme of Attitude Taxonomy in UAM CorpusTool

However, the researcher has modified three features: attitude polarity, appraiser, and appraised. To illustrate, the ambiguous variable has been deleted in order to avoid any unclear emotions. Second, the appraiser refers to the nationalities of the commentators: Americans, Europeans, Australians, and Canadians. This helps identify the ideology of each community towards the existence of the Syrian refugees in the West. Finally, the subdivisions of the appraised feature: self and other have been modified. That is, the 'self' points to the origin of the speaker to express his/her own feelings and views. On the other hand, the 'other' refers to the Syrian refugees, a feature which is in turn classified into men, women, children, women and children, and all. The rationale behind such modifications is to achieve accuracy and consistency. It is noteworthy that these changes are a contribution to the present study. Figure (2) shows the researcher's modifications:

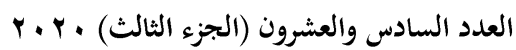


The Representation of the Syrian Refugees in the Westerners' Comments on

Facebook Refugee images in 2015: Corpus-based Multimodal Analysis

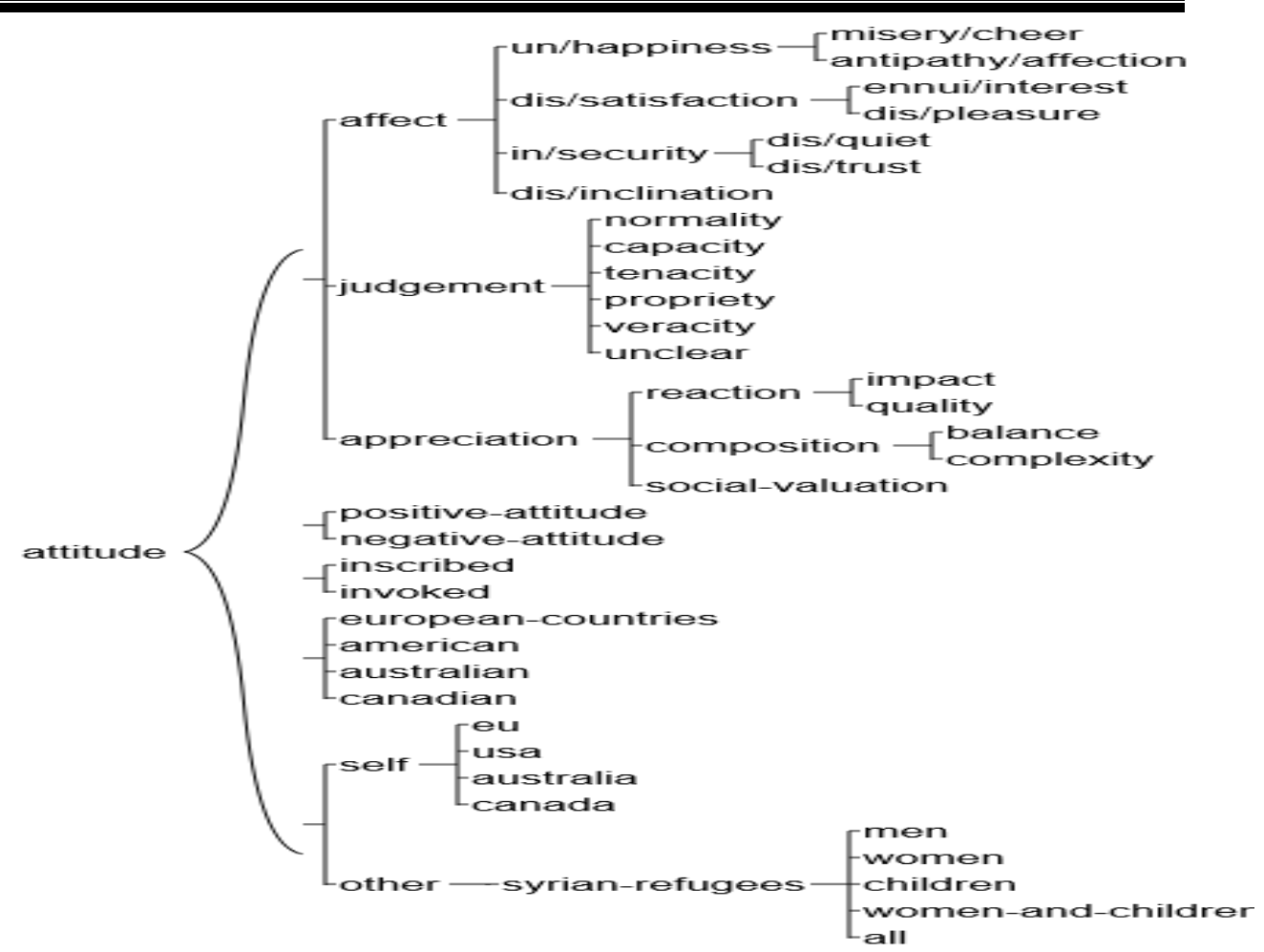

Figure (2) The researcher's modifications to the Attitude taxonomy in the built-in scheme of UAM CorpusTool

\subsection{Procedures}

The process of data collection has followed some steps: (1) The search started with writing 'syrian refugees in Europe, on borders, in camps, or in host countries', (2) Then the researcher determined the year under the time icon, which was '2015' to get all the images that were posted during this year, (3) The researcher selected the images which recorded the greatest percentage of emojis and shares. To guarantee that the image belonged to the Syrian refugees, the researcher followed two steps: reading the caption posted by the entity (i.e. online newspaper that publicized the image on Facebook and making sure that the commentators'

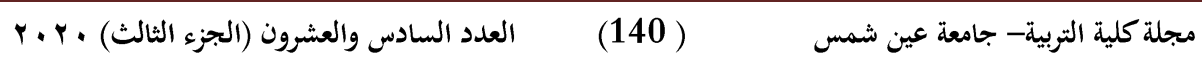


comments referred to Syrian refugees only, and that the Syrian refugees captured in the images were real, not caricatured. Therefore, meme images were not acceptable in the study. (4) All the comments that contained non-English words and Franco-Arabic letters were discarded, such as 'astaghfiruAllah' (ask Allah for forgiveness), (6) the data comments included only the westerners: Americans, Europeans, Canadians, and Australians. Therefore, any other nationalities were deleted. The commentators, whose nationalities were unknown, were also excluded. The objective was to discuss how the western communities commented on their feelings towards the Syrian refugees and described their conditions in the host countries. It is noteworthy that such commentators either hosted the Syrian refugees in their countries or they were waiting for their arrival.

\subsection{Data Preprocessing}

Before analyzing the data collected, the researcher preprocesses the data in different ways. That is, the comments are extracted from Facebook and then pasted in Microsoft Word program to be edited. First, the data are edited for spelling, such as 'islamafaubia' (Islamophobia) and 'I till you' (I tell you). Acronyms are not edited, but the researcher has decoded them in the comment application on UAM CorpusTool, for example the acronym 'smh' (shake my head) to express disappointment. In this stage, the researcher also searches for the nationality of each commentator and records it in a separate word file as it is not inserted in the text files. The researcher only glances over these nationalities during the annotation.

\subsection{Theoretical Framework}

The present study aims to explore the representation of the Syrian refugees in the western commentators' discourse on Facebook. This is performed through showing how they positively or negatively evaluate the refugees' emotions, behaviour, and conditions. In this respect, the researcher adopts the appraisal framework which provides a discursive method through which

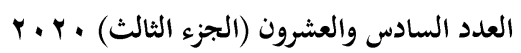

(141) 
The Representation of the Syrian Refugees in the Westerners' Comments on

Facebook Refugee images in 2015: Corpus-based Multimodal Analysis

speakers express feelings and opinions to assess other people, things, or situations in a given text. In this way, the speaker/ writer attitudinally and ideologically positions the audience/reader towards those people, things, or situations (Martin \& White, 2005,p.184). In this regard, the researcher focuses on the attitude, a subdivision of the appraisal theory. Attitude is further classified into three subsystems: affect, judgement, and appreciation.

\subsubsection{Attitude}

The researcher selects attitude as a subcategory of the appraisal theory to show the positive and negative representation of the Syrian refugees' sentiments, ethics, identities, and conditions in the western commentators' discourse on the refugees' Facebook images. Martin and White (2005) define the attitude as a "system [that] involves three semantic regions covering what is traditionally referred to as emotion, ethics and aesthetic" (p.42). The three semantic components of attitude are affect which tackles emotions; judgment which discusses ethics; and appreciation which evaluates aesthetics (p.42).

\section{Affect}

Affect is the first subdivision of attitude. Martin and White (2005) define it as a way through which writers/speakers positively or negatively appraise people's emotions, events, and states in a given discourse (Martin \& White, 2005, p.2). The present study applies affect to the western commentators' discourse to show their feelings towards the Syrian refugees in addition to describing the refugees' emotions in different situations. In this respect, Martin and White (2005) state that the one, who experiences the emotion, is called 'Emoter', whereas the persons/objects, that the emotion is targeted at, are named 'Trigger'. Such emotions provoke dis/inclination which shows un/desirable attitude. In addition to

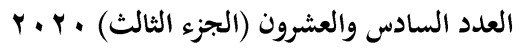

مجلة كلية التربية- جامعة عين شمس 
disinclination, there are three further variables under affect: un/happiness, in/security, and dis/satisfaction. Each variable is classified into subsystems. Un/Happiness is concerned with whether evaluations are positive or negative. It is divided into happiness: affection "hug" and cheer "laugh" and unhappiness: misery "cry" and antipathy "hate". Besides, in/security discusses whether feelings targeted at the Trigger are peaceful or anxious. It embraces both security, like confidence (proclaim) and trust (entrust), and insecurity: surprise (faint) and disquiet (restless). Finally, dis/satisfaction demonstrates both achievement and frustration (pp.48-51).

\section{Judgement}

Judgement is the second type of attitude. It is interested in assessing people's behaviour and characteristics. It is classified into two subdivisions: social esteem which shows attitudes of admiration and criticism and social sanction through which the emoters expresses how far they praise or condemn people. Judgments of esteem are divided into normality (how ab/normal somebody is), capacity (how un/able they are), and tenacity (how un/determined they are). The examples of social esteem variables are 'un/usual', 'weak/powerful', and 'coward/brave' respectively. Such instances exist in chats, jokes, and everyday conversations. On the other hand, 'judgments of sanction' tackle two variables: veracity (how un/trustworthy somebody is) and propriety (how im/moral somebody is). Such instances are catalogued in writing, like rules, decrees and laws. The instances of social sanction are "dis/honest" and "im/moral" respectively (Martin \& White, 2005, pp.52-53). In this regard, Judgement plays an important role in praising or condemning the Syrian refugees' ethics and their commitment towards the rules and regulations in the host countries.

\section{Appreciation}

Appreciation is the last type of attitude which demonstrates the region of meaning that discloses positive and negative

r.r. r. العدد السادس والعشرون (الجزء الثالث)
مجلة كلية التربية- جامعة عين شمس 
The Representation of the Syrian Refugees in the Westerners' Comments on

Facebook Refugee images in 2015: Corpus-based Multimodal Analysis

'evaluations' of objects, especially actions we perform and decisions we make'. Appreciation is divided into three variables: 'reaction' (do they grab our attention; do they make us happy?), their 'composition (balance and complexity)', and their valuation that shows how credible or innovative something is. Examples of appreciation subdivisions which include positive and negative evaluations are illustrated in "un/remarkable" (reaction), "harmonious/flawed" (composition:balance), "precise/unclear" (composition: complexity), and "unique/common" (valuation) (Martin \& White, 2005, pp.5658). The following diagram discusses how judgment and appreciation are institutionalized.

ethics/morality (rules and regulations)

feeling institutionalised as proposals

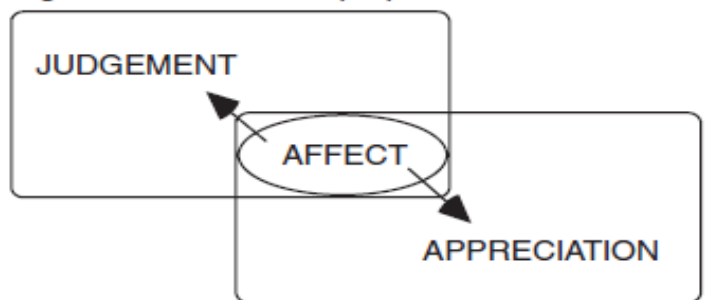

feeling institutionalised as propositions aesthetics/value (criteria and assessment)

Figure (3) Judgment and Appreciation as Institutionalized Affect (Martin \& White, 2005, p.45)

The diagram shows an orientation to affect as a common factor between judgment and appreciation because both of them express feelings. Martin and White (2005) regard judgment and appreciation as institutionalized feelings. That is, judgment deals with emotions towards humans' behavior and towards rules as well as regulations held by state. On the other hand, appreciation demonstrates feelings as propositions about the value of things.

In addition, there are inscribed and invoked realizations beyond the grammatical structures, As for inscriptions, they are used to function as 'sign-posts' and to understand the ideational

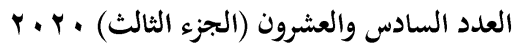

مجلة كلية التربية- جامعة عين شمس 
realisations that convey the intended meaning (Martin \& White, 2005, pp.74-75). For example, 'It's heartbreaking' is a comment said by an American commentator to describe the terrible situation of the Syrian refugees. The instance shows an inscribed negative appreciation of the situation realized by the commentator. On the other hand, invocations are the lexical choices made to indirectly reflect positive or negative evaluations (Martin \& White, 2005, p.65). For instance, a British commentator states that 'all they want is to be safe' is an invoked negative affect (i.e. insecurity) as the commentator indirectly shows that the refugees are insecure.

\subsection{Critical Discourse Analysis (CDA)}

The rationale of using the Critical Discourse Analysis as a method is that the researcher aims to demonstrate the western commentators' ideology in representing the Syrian refugees (negative/positive Other representation). In this respect, van Dijk (2005) defines CDA as

a type of discourse analytical research that primarily studies the way social power abuse, dominance, and inequality are enacted, reproduced, and resisted by text and talk in the social and political context. With such dissident research, critical discourse analysts take explicit position, and thus want to understand, expose, and ultimately resist social inequality. (p.352).

CDA highlights the social and political issues rather than only studies how the discourse is structured. It also focuses on the ideology hidden in the text to take a social action against such problems (van Dijk, 2015, p.467). In this respect, van Dijk (2000) defines ideologies as the main thoughts shared by a group and its members (p.7). Consequently, such thoughts are acquired, practiced, and differed according to the group members' situations, interests, and relations in a society (van Dijk, 1998, p.135).

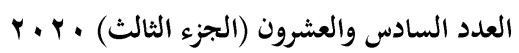


The Representation of the Syrian Refugees in the Westerners' Comments on

Facebook Refugee images in 2015: Corpus-based Multimodal Analysis

\subsection{Multimodal Critical Discourse Analysis}

Multimodality is widely discussed by linguists and semioticians. It analyzes the basic pillars that allow the viewer to comprehend the meaning potential through placing the components of an image and constructing its framing, salience proximity, and colour saturations (Machin, 2007, p. ix-x). Regarding Multimodal Critical Discourse Analysis (MCDA), Machin and Mayr (2012) highlight the way images are structured and used in a context to make meaning in a given text. The authors also consider how multimodality is incorporated in CDA to discuss the ideology of the multimodal discourse: text and image (pp.6-7). In the present study, the refugees' way of clothing, postures, and facial expressions reveal their identity. Therefore, the critical analysis of the images helps to convey an additional meaning hidden in texts.

\subsubsection{Visual Semiotic Choices}

The present study demonstrates four semiotic choices: iconography, attributes, setting, and salience. As for iconography, Machin and Mayr (2012) state that the images are analyzed through denotation and connotation, depending on the context in which the image is used. First, images record specifications, people, places, and things. That is, a picture of a house denotes a house. In addition, the image is a connotation of thoughts and ideas. For example, the house image connote richness and luxury (p.49).

In addition, the authors shed light on attributes as a semiotic choice to reveal thoughts and qualities conveyed by objects and their representations in images. In other words, each object in the image provides a different characteristic in the person. The authors adopt an example from Cosmopolitan magazine where there is an image of a woman. The analysis of the image depends on the objects around the woman: the PC computer, a handbag, and a clean empty desk. All these objects denote that she is at work, while the PC computer signifies mobility and independence. In addition, her way of clothing

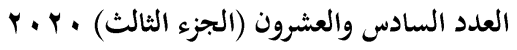

مجلة كلية التربية- جامعة عين شمس 
is also regarded. The high-heeled shoes and the handbag represent her fashionable style. The short skirts, the loose scarf around her neck, revealing tops, and the shiny red lipstick connote her sexuality and man desire. This sexuality is the source of her power and success over men (Machin \& Mayr, 2012, pp. 50-52).

Regarding settings, they are an example of visual resource to communicate thoughts. They also reflect the social values, identities, and actions. In the previous example of the Cosmopolitan woman's image, the setting reflects a work environment. However, the woman does not use the computer to perform any activities. The desk is also clean and empty, reflecting the luxury of space. The image signifies modernism, optimism, creativity, and excitement (Machin \& Mayr, 2012, p. 53).

Concerning salience, Machin and Mayr (2012) highlight the fact that salience lies in specific traits to grab the viewers' attention to expect particular meanings. The symbolic ways through which salience can be achieved are explained. First, 'potent cultural symbols' tell ideas about the culture of people. For example, the stethoscope connotes medical practice. Second, size shows how important the person/object in the picture is. The bigger the object/person in the image is, the more important it becomes. Third, colour is an important icon to consider the importance of the person/object. The most saturated colourful object is the most important one. Fourth, the tone brightens the object/person that is the most outstanding element in the image. Fifth, focus raises the essentiality of an element by heightening it to exaggerate details and fade away the unnecessary. Sixth, foregrounding causes elements to be salient by bringing objects/ persons in the foreground while other elements are in the background (pp.54-56).

\subsubsection{Representing Speakers' Attitude through Visual Semiotic Choices}

Machin and Mayr (2012) state that gaze is a part of poses as it focuses on how people look upwards and downwards; it holds a 
The Representation of the Syrian Refugees in the Westerners' Comments on

Facebook Refugee images in 2015: Corpus-based Multimodal Analysis

relationship between the viewer and the participant (p. 70). In this regard, Halliday's (2004) speech acts are highlighted: giving information, demanding information, giving goods and services, demanding goods and services (p.104). For example, the present study provides an image of a young Syrian man who is smiling at the viewer as if he requests him to smile in return, giving a positive energy to the viewer.

However, looking off the frame rather than an object in the image triggers the viewer to think what the participant is thinking of (demand image). Looking up or down is also metaphorical. That is, the western culture regards upwards as high status and the opposite is conveyed when looking downwards. Gordon Brown is captured while looking downwards, thinking; this means that he has negative thoughts. The image does not invite the viewer to have any interaction, but to be an observer (Machin \& Mayr, 2012, p.73).

Moreover, Machin and Mayr (2012) state that poses connote the identities of the people in images. The authors show an image where a woman is working at her laptop, sitting on stairs, and smiling to the viewer, so this demonstrates that the physical space is also regarded. Therefore, analysts should ask whether or not the space will be taken into consideration and whether it is an open or closed one. In addition, whether a pose provokes an activity or stillness is also explored. Moreover, poses show if the participant in the image is self-controlled (i.e. soldiers) or loose (i.e. teenagers) (pp.74-75).

\subsubsection{Interactional Strategies in Visual Communication}

To position the viewer in relation to people inside the image, Machin and Mayr (2012) provide two pillars: distance and angle. Distance signifies the social relation between the participant and the viewer. In images, distance is the 'size of frame' (close, medium, or long shot). The authors provide an image of David Cameron whose

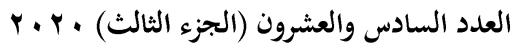

مجلة كلية التربية- جامعة عين شمس 
closer shot shows that he is worried (pp.96-97). As for angle, the viewer engages with participants in the image by having face-toface looking. Sometimes, the participant does not look right to the viewer, so it is a kind of observation on the part of the viewer. The side-on view connotes a close solidarity. Besides, the viewer either looks down or looks up to participants. For example, viewers look up at David Cameron to show his power.

\subsection{UAM CorpusTool Software}

UAM CorpusTool is software designed to annotate text corpora, using a built-in scheme. It also enables the user to design his own scheme and adds layers of annotation. It facilitates analysis on multiple text levels: word level, phrase level, sentence level, or document level. In addition, an automatic retrieval of results can be easily performed on the software, so statistical analysis is available. The annotation is either automatic, manual, or mixed (UAM Corpus Tool 3.0, 2012). In this sense, the researcher uses this software to annotate the attitudinal items, regarding affect, judgement, and appreciation. Some modifications are added to achieve accuracy and consistency in the study results. The researcher manually annotates the texts and then automatically retrieves the results.

\section{Literature Review}

Lemke (2002) coined the term "hypermodality" to refer to the verbal-visual interactions and to demonstrate the interpretations resulted from sound forms in a hypertext. Depending on the social semiotic approach performed by Kress and van Leeuwen (1996), the researcher conducted a study to propose one fruitful way to interpret the combinations of 'the presentational, orientational, and organizational resources of each semiotic mode'. His study highlighted the links between the text, image, and sound in a given context selected from a web of pages (p.300). He applied the approach on five web images taken from the National Aeronautic and Space Administration (NASA) Earth Observatory. In his conclusion, the analysis showed that there were semiotic, semantic,

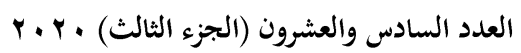

$(149)$ 
The Representation of the Syrian Refugees in the Westerners' Comments on

Facebook Refugee images in 2015: Corpus-based Multimodal Analysis

and political functions to make precise meanings and perform accurate reasoning in the hypertexts (pp.304-320).

Hansen and Machin (2008) performed a study on a number of images taken from Getty Images, 'the largest supplier of stock images in the world', where semiotic choices were used for encouraging advertisements, promotions, and marketing purposes. The researcher used both the Critical Discourse Analysis (CDA) and the semiotic resources to discuss the ideology behind the recontextualization of images for motivating people to be friendly to the environment. Getty images were characterized by three features: 'substitution', 'addition', and 'evaluation'. In substitution, generalizations replace the detailed activities, and the participants in the images were described through their appearance and setting. As for addition, the website recontextualized the images through the target and 'reactions'. This was performed by exploring the participants' emotions and deeds in the images. Concerning evaluation, the analysts appraised the participants' actions, and hence identified the ideology. Therefore, the multimodal discourse analysis enabled the researcher to analyze the images and stressed the values and identities signified in the social actors' actions for the sake of marketing and advertising (pp.777-781).

El Melligy (2013) used appraisal theory as a framework and tool of analysis to find out the appraising items and attitudinal realizations to qualitatively analyze how El Jazeera English and the BBC online websites discussed the Egyptian Revolution (2011). The researcher analyzed the news reports through extracting Appraisal subsystems: Attitude, Engagement, and Graduation, with regard to the register and genre (p.ii). She explored that it was impossible to be neutral while reporting the news, and that subjectivity was evident in their reporting with different attitudes, grading, and involvement (pp.84-85).

r.r. العدد السادس والعشرون (الجزء الثالث)

مجلة كلية التربية- جامعة عين شمس 
Tupala (2019) conducted a study on the institutional documents on migration in the European Union, using the appraisal framework. Although the documents were expected to be factual and objective, the researcher proved that they were attitudinal and evaluative. The researcher enhanced the study of the appraisal theory in a corpus-based study, using UAM CorpusTool. The results discussed six main points: the annotation was manual, a corpus tool always helped analyze the data, analyzing individual words was not enough, adding modifications to the corpus program scheme was essential, quantitative analysis was fruitful, and the annotation of the wordings depended on the context.

\subsection{The Appraisal Theory (AT)}

\subsubsection{Definition and Overview}

Martin and Rose (2007) define appraisal as 'a system of interpersonal meanings'. The appraisal framework studies evaluation: the types of attitudes that are "negotiated" in a discourse, the power of the emotions expressed and the techniques in which qualities are originated, and readers are brought to dis/alignment (p.22). The rationale of using the appraisal theory in the present study is to discuss the negative/ positive feelings of the Syrian refugees. It also highlights the Syrians' behaviour and evaluates their conditions in the camps of the western countries.

3.1.2 Appraisal Theory and Systemic Functional

\section{Grammar (SFG)}

Appraisal theory is developed from Halliday's approach of Systemic Functional Grammar (SFG). Halliday (2004) states that language is a way of interaction among participants to give or demand goods and services (p.107). It expresses sentiments and respond to the stances communicated in a given text. It tackles the subjective interpersonal metafunction and emphasizes the opinions adopted by speakers/writers in a certain text towards a particular issue (Martin \& White, 2005, p.1).

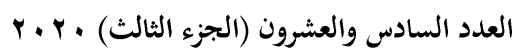

مجلة كلية التربية- جامعة عين شمس 
The Representation of the Syrian Refugees in the Westerners' Comments on

Facebook Refugee images in 2015: Corpus-based Multimodal Analysis

In this respect, Halliday (2004) provides three metafunction that is clear in any text and talk: ideational, interpersonal, and textual. The ideational metafunction constructs the exchange of human experiences. On the other hand, the interpersonal metafunction depends on the linguistic features that show the relations between writers/speakers and readers/hearers, whereas the textual metafunction controls the flow of text and talk, and maintains its coherency (pp.29-30). The appraisal theory is interested in the interpersonal metafunction as it underpins the intersubjective stances of speakers/writers in a given text and how they affect the views and emotions of the target hearers/readers.

Similarly, Martin and White (2005) consider appraisal as 'an interpersonal system at the level of discourse semantics' along with negotiation and involvement. As for negotiation, it focuses on the 'interactive' dimensions of 'discourse, speech function and exchange structure'. Moreover, involvement aligns with appraisal by confirming 'non-gradable' qualities for tackling 'tenor relations', particularly 'solidarity' (p.33). To illustrate, in the present study, the discourse enables the commentators to discuss the refugees' emotions, ethics, and circumstances reflecting a specific ideology.

\subsubsection{Appraisal Theory and Discourse Semantics}

Appraisal is introduced in discourse semantics for three reasons. Firstly, the attitude realized is noticed in 'a phrase of discourse' regardless of 'grammatical boundaries'. For example, in the utterance 'Great! Great! Great! It's really good news. I'm glad that you succeeded', the repetition of the adjective 'great', the adverb 'really', the adjectives 'good' and 'glad', and the verb 'succeeded' show a positive evaluation. Secondly, as shown in the previous example, the attitude is evaluated through a variety of syntactic structures. In this case, the interlocutor (emoter) moves out of 'lexicogrammar' to generally show the appraised meaning (ideology). Thirdly, appraisal is also concerned with 'grammatical

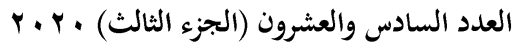

مجلة كلية التربية- جامعة عين شمس 
metaphor' which expresses an attitude and grading views (Martin \& White, 2005, p.10). In the instance, 'it's a tragedy', the emoter expresses a negative attitude, evaluating the Syrian refugees' conditions on the European borders. However, the present study does not focus on how strong the commentators' attitudinal expressions are.

\subsubsection{Appraisal and Identity}

The concept of identity is discussed in the study to identify how the existence of the Syrian refugees in the western host countries will affect their identity. That is, the refugees have Arabic, Islamic culture and lifestyle; however, they are going to be assimilated with the western laws, thoughts, and traditions. In addition, the Civil War launched in Syria has an impact on their ideas, personalities, and concepts. These conditions consequently reshape the Syrian refugees' identity. This is also clear in their images on Facebook and in the westerners' views.

In this regard, Oyserman et al (2012) define identity:

They are the traits and characteristics, social relations, role, and social group memberships that define who one is. Identities can be focused on the past ... the present ... or the future .... Identities are orienting, they provide a meaning-making lens and focus one's attention on some but not other features of the immediate context (p.69).

Both the attitudinal realization and visual semiotic features critically demonstrate the refugees' identity.

\subsection{Approaches}

\subsubsection{Social Semiotics Approach}

The social semiotics approach is adopted to qualitatively analyze the images of the Syrian refugees. In this respect, van Leeuwen (2005) also defines semiotic resources as actions

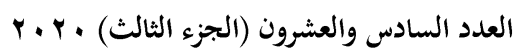


The Representation of the Syrian Refugees in the Westerners' Comments on

Facebook Refugee images in 2015: Corpus-based Multimodal Analysis

performed by using facial expressions or gestures without being constrained to a specific genre. They focus on how people produce signs and what such signs mean, and hence some cultural and social meanings are conveyed (p.3). For example, the present study provides an image of some Syrian refugees who are dressed in rich coats, signifying that they belong to an upper-middle social class; however, they are humiliated by fleeing on flimsy boats to save their lives against the Civil War in Syria. In the current study, the researcher adopts the semiotic resources developed by Machin and Mayr (2012).

\subsection{Corpus Linguistics}

McEnry and Wilson (1996) state that corpus linguistics is a methodology that tackles a lot of ways for language study, such as concordance. It is a 'heterogeneous field' (p.1). Gries (2009) defines corpus as

a machine-readable collection of (spoken or written) texts that were produced in a natural communicative setting, and the collection of texts is compiled with the intention (1) to be representative and balanced with respect to a particular linguistic variety or register or genre and (2) to be analyzed linguistically (p7).

The rationale of providing a corpus-based study is to facilitate annotating the data, performing an automatic retrieval of the results, and exploring the ideologies of the commentators.

\subsubsection{Frequency List}

Gries (2009) states that frequency list is one of the most necessary tools in Corpus Linguistics. It is used to count how many times a specific word or pair of words has taken place in the corpus. It is designed in two-column table in which the types are in one column and their token frequencies are in the other column (p.12).

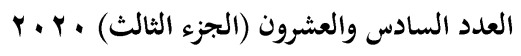

مجلة كلية التربية- جامعة عين شمس 
In this study, the researcher uses the frequency list to find out the frequency of appraisal variables mentioned in the Facebook comments. For example, the comment 'so sad' is appraised under negative attitude (appreciation: reaction: quality) as it evaluates the sad conditions that the refugees experience. In this sense, the UAM CorpusTool automatically counts the frequency of the variables to find out the ideology.

\section{$4 \underline{\text { Analysis }}$}

The data are analysed through several steps. First, on the verbal level, the researcher manually annotates the attitudinal realisations, concerning affect, judgement, and appreciation. Then the results are automatically retrieved to discuss how the Syrian refugees in the western commentators' discourse are negatively/positively depicted. In addition, the ten images of the Syrian refugees are qualitatively analysed to appraise how the Syrian refugees are visually represented, and hence the ideology is identified.

\subsection{The Negative Representation of the Syrian Refugees in the Westerners' discourse}

The researcher starts by explaining how appreciation is used in the western commentators' discourse as it is the most representative feature. The annotation tackles the three subsystems: reaction including quality and impact, composition whether it is unbalanced or complex, and social valuation.

In the following tables, there are some abbreviations needed to be discussed in advance. First, under appraised column, the researcher labels Syrian refugees as (SR), Syrian men as (SM), Syrian women as (SW), Syrian children as (SC), refugees' journey as $(\mathrm{RJ})$, and refugees' boat (RB). The negative/positive evaluations are referred to as $(-) /(+)$ before the feature that categorizes the appraising item. The inscribed examples are abbreviated as (ins.), while the invoked ones are (inv.). This is applied to all the tables in the analysis.

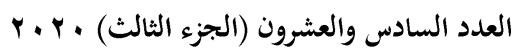

مجلة كلية التربية- جامعة عين شمس 
The Representation of the Syrian Refugees in the Westerners' Comments on

Facebook Refugee images in 2015: Corpus-based Multimodal Analysis

In addition, appreciation is divided into three categories: reaction (React.) which is further classified into impact (I) and quality (Q), composition (Comp.) which is classified into balanced (B) and complex (C), and social valuation (val.).

\begin{tabular}{|c|c|c|c|c|c|c|}
\hline \multirow{3}{*}{$\begin{array}{c}\text { Post } \\
\#\end{array}$} & \multirow{3}{*}{ Appraising items } & \multirow{3}{*}{ Appraiser } & \multicolumn{3}{|c|}{ Appreciation } & \multirow{3}{*}{$\begin{array}{l}\text { Appr } \\
\text { aised }\end{array}$} \\
\hline & & & React. & Comp & \multirow[t]{2}{*}{$\begin{array}{l}\text { Social } \\
\text { Val. }\end{array}$} & \\
\hline & & & $\mathbf{Q}$ & \begin{tabular}{l|l}
$\mathbf{B}$ & $\mathbf{C}$ \\
\end{tabular} & & \\
\hline 17 & $\begin{array}{l}\text { This picture's } \\
\text { absolutely } \\
\text { heartbreaking }\end{array}$ & Spain & - Q/ ins. & & & SR \\
\hline 18 & $\begin{array}{l}\text { These pictures are very } \\
\text { upsetting }\end{array}$ & Germany & $-\mathrm{Q} /$ ins. & & & SR \\
\hline 18 & it's a big tragedy & Canada & $-Q /$ ins. & & & SR \\
\hline 14 & Traumatic & Australia & - Q/ ins. & & & $\mathrm{SC}$ \\
\hline 18 & despicable & Australia & $-\mathrm{Q} /$ ins. & & & SR \\
\hline 7 & $\begin{array}{l}\text { terrifying for all these } \\
\text { children }\end{array}$ & USA & - Q/ ins. & & & $\mathrm{SC}$ \\
\hline 14 & not fair & Australia & & & $\begin{array}{l}\text { - val./ } \\
\text { ins. }\end{array}$ & $\mathrm{SC}$ \\
\hline 14 & not humane & Australia & & & $\begin{array}{l}\text { - val./ } \\
\text { ins. }\end{array}$ & $\mathrm{SC}$ \\
\hline 2 & $\begin{array}{l}\text { desperate times for } \\
\text { these people }\end{array}$ & USA & & $\mathrm{C} /$ ins. & & $\begin{array}{l}\text { SW } \\
\& \\
\text { SC }\end{array}$ \\
\hline 3 & $\begin{array}{l}\text { what is happening to } \\
\text { Syrian women and } \\
\text { children is also a } \\
\text { disgrace }\end{array}$ & USA & & & $\begin{array}{l}\text { - val./ } \\
\text { ins. }\end{array}$ & $\begin{array}{l}\text { SW } \\
\& \\
\text { SC }\end{array}$ \\
\hline 18 & incredibly sad! & USA & - Q/ ins. & & & SR \\
\hline 17 & a flimsy boat & Ireland & & $\begin{array}{l}\text {-B/ } \\
\text { ins. }\end{array}$ & & $\mathrm{RB}$ \\
\hline 7 & hazardous trip & USA & & $\begin{array}{l}\mathrm{C} / \\
\text { ins. }\end{array}$ & & RJ \\
\hline 7 & rough trip & USA & & $\begin{array}{l}\mathrm{C} / \\
\text { ins. }\end{array}$ & & RJ \\
\hline
\end{tabular}

r. r. العدد السادس والعشرون (الجزء الثالث)

مجلة كلية التربية- جامعة عين شمس 
Table (1) The Negative Appreciation of Syrian Refugees in the Western Comments on Facebook

As shown in the table, the inscribed realizations of appreciation are common as the commentators openly discuss the Syrian refugee crisis. They cover the threatening image of Syrian refugees as their situation is described as 'a big tragedy', 'traumatic', 'terrifying', and 'despicable'. This is reflected in their pictures which are 'very upsetting'. Then the commentators deeply tackle every detail by sharing their feelings with the refugees in general and the Syrian women and children in particular. To illustrate, they represent the reaction of the Syrian refugees by using expressions, like 'absolutely heartbreaking'. They are in a critical situation, either they are on their way to the western community or on the borders of the host countries. Besides, the commentators show the negative social valuation of the mistreatment that the Syrian refugees receive at the hand of the Hungarian policemen on the Hungarian borders. They describe the situation as a 'disgrace', 'not fair', and 'not humane'. To explain, the tribulations encountered by the women and their children on their traveling from Syria to Europe is a disgrace. Instead of being protected and of living a peaceful life, the Syrian children become traumatized refugees, whereas the Syrian women turn to be lost with their kids. The boats that take them from Syria to Europe are described as 'flimsy' or flawed. This is clear that the boats are neither balanced nor prepared enough to transport the refugees. To add fuel to the fire, Syrian women and their children spend a lot of 'desperate times' on the European borders, resulting in chaos. For example, the refugees are mistreated by the Hungarian police officers; the treatment is described as 'not humane', resulting in the refugees' protests to gain the right of asylum seeker. Therefore, the whole situation is 'incredibly sad' as the children's emotions are complex and unstable. That is, they have witnessed a lot of fearful circumstances during their 'hazardous' and 'rough' trip to Europe. That is why their life becomes too complex to be bearable.

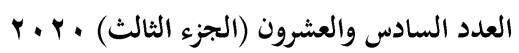


The Representation of the Syrian Refugees in the Westerners' Comments on

Facebook Refugee images in 2015: Corpus-based Multimodal Analysis

In the following table, the researcher discusses the refugees' behaviour and attitude from the perspective of the western commentators. The commentators express their opinions towards the refugees' ethics. The annotation demonstrates both the social esteem subcategories: capacity (Cap.), normality (norm.), and tenacity (Ten.), and the social sanction: propriety (Prop.).

\begin{tabular}{|c|c|c|c|c|c|c|c|}
\hline \multirow{3}{*}{$\begin{array}{c}\text { Post } \\
\#\end{array}$} & \multirow{3}{*}{$\begin{array}{l}\text { Appraising } \\
\text { items }\end{array}$} & \multirow{3}{*}{ Appraiser } & \multicolumn{4}{|c|}{ Judgment } & \multirow{3}{*}{ Appraised } \\
\hline & & & \multicolumn{3}{|c|}{ Social esteem } & \multirow{2}{*}{$\begin{array}{c}\begin{array}{c}\text { Social } \\
\text { sanction }\end{array} \\
\text { Prop }\end{array}$} & \\
\hline & & & Cap & Norm & Ten & & \\
\hline 19 & $\begin{array}{l}\text { these poor } \\
\text { people have no } \\
\text { money }\end{array}$ & USA & $\begin{array}{l}\text { - Cap/ } \\
\text { ins. }\end{array}$ & & & & SR \\
\hline 2 & Exhausted & USA & $\begin{array}{l}\text { - Cap/ } \\
\text { ins. }\end{array}$ & & & & SR \\
\hline 2 & Spent & USA & $\begin{array}{l}\text { - Cap/ } \\
\text { ins. }\end{array}$ & & & & SR \\
\hline 28 & $\begin{array}{l}\text { poor wretched } \\
\text { family }\end{array}$ & UK & $\begin{array}{l}\text { - Cap/ } \\
\text { ins. }\end{array}$ & & & & SR \\
\hline 2 & $\begin{array}{l}\text { Poor little } \\
\text { darlings }\end{array}$ & Australia & $\begin{array}{l}\text { - Cap/ } \\
\text { ins. }\end{array}$ & & & & $\mathrm{SC}$ \\
\hline 8 & Thirsty & Canada & $\begin{array}{l}\text { - Cap/ } \\
\text { ins. }\end{array}$ & & & & \\
\hline 18 & $\begin{array}{l}\text { completely } \\
\text { disorganized }\end{array}$ & France & $\begin{array}{l}\text { - Cap/ } \\
\text { ins. }\end{array}$ & & & & SR \\
\hline 18 & Madmen & USA & & $\begin{array}{l}\text { - Norm/ } \\
\text { ins. }\end{array}$ & & & SM \\
\hline 3 & war victims & USA & & $\begin{array}{l}\text { - Norm/ } \\
\text { ins. }\end{array}$ & & & SR \\
\hline 7 & a suffering child & USA & & $\begin{array}{l}\text { - Norm/ } \\
\text { ins. }\end{array}$ & & & $\mathrm{SC}$ \\
\hline 18 & Brutal & Hungary & & & & - Prop/ ins. & SM \\
\hline
\end{tabular}

r. r. العدد السادس والعشرون (الجزء الثالث)

مجلة كلية التربية- جامعة عين شمس 
Mai Anas Lotfy Mohammad Zahra

\begin{tabular}{|l|l|l|l|l|l|l|l|}
\hline 18 & $\begin{array}{l}\text { rioting and } \\
\text { becoming } \\
\text { increasingly } \\
\text { violent }\end{array}$ & USA & & & & - Prop/ ins. & SM \\
\hline 21 & $\begin{array}{l}\text { Trojan Horse for } \\
\text { ISIS }\end{array}$ & USA & & & & - Prop/ ins. & SM \\
\hline 3 & illegal people & USA & & & & - Prop/ ins. & SR \\
\hline 21 & $\begin{array}{l}\text { potential jihadi } \\
\text { fighters }\end{array}$ & USA & & & & - Prop/ ins. & SM \\
\hline 18 & $\begin{array}{l}\text { Throwing stones } \\
\text { at the Hungarian } \\
\text { police }\end{array}$ & Hungary & & & & & \\
\hline 21 & $\begin{array}{l}\text { Bunch of } \\
\text { cowards }\end{array}$ & USA & & & $\begin{array}{l}- \text { Ten/ } \\
\text { ins. }\end{array}$ & & SR \\
\hline 2 & $\begin{array}{l}\text { Cowards run } \\
\text { away }\end{array}$ & Greece & & & $\begin{array}{l}- \text { Ten/ } \\
\text { ins. }\end{array}$ & & SM \\
\hline
\end{tabular}

Table (2) Negative Judgement of Syrian Refugees in the Westerners' Comments on Facebook

The table discusses the negative judgment of the Syrian refugees in the western commentators' discourse. Regarding capacity, the commentators reflect the refugees' helplessness. The examples that describe their states are 'spent', 'poor', 'thirsty', and 'exhausted', and 'have no money'. They have neither power nor potential to do anything. They are penniless and so tired out of exhaustion and thirst, so they cannot bear the bad circumstances they are facing.

As for normality, the commentators disclose how they think of the personal nature of these refugees. In other words, the Syrian refugee men are shown as 'madmen' for their insane reaction (i.e. protests against the Hungarian authorities on the borders). The Syrian children are described as 'suffering' humans as they are victimized by the wrong decisions of their parents, and the general description of the refugees is that they are 'war victims' as they experience a lot of repercussions for the Civil War in Syria .

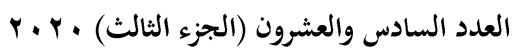


The Representation of the Syrian Refugees in the Westerners' Comments on

Facebook Refugee images in 2015: Corpus-based Multimodal Analysis

In addition to capacity and normality, tenacity also unveils how the Syrian refugee men are negatively represented. It is remarkable that all western commentators agree upon the fact that the Syrian men are 'cowards' because they run away from Syria instead of fighting for regaining its freedom and stability. Some of them believe that male refugees escape the Civil War, abandoning their families in the hell there. Therefore, the examples show that the westerners' opinions concerning the Syrian refugees in general and men in particular threaten the identity of the Syrians.

As for the propriety, the illustrative realizations show the negative evaluation of the Syrian refugees in general and the Syrian refugee men in particular. To exemplify, the refugees' general ethical behavior is shown as 'illegal'. That is, they flee to the western countries without having an asylum right or their own documents to be legally registered as asylum seekers. It is also noteworthy that the Hungarians and Romanians are the commentators that describe the Syrian men as 'brutal' and 'violent' respectively as they are the ones who experience the continuous influx of the Syrian refugees into their borders. They witness how the refugees riot against the authorities and throw stones against the border officers to let them pass the borders. Hungarians and Romanians are the ones who suffer more than other European countries because they are closer to Syria than the other countries. As a result, the westerners' fears against the existence of the Syrian refugees drive them to think that the male refugees are 'Trojan Horse for ISIS' and 'potential jihadi fighters'. To explain, the commentators are so terrified that they can believe that the Islamic State exploits the refugee crisis and sends ISIS infiltrators. That is why they call them potential jihadi fighters.

The following table discloses the negative affective attitude of the Syrian refugees according to the western commentators' views. It tackles four subsystems: unhappiness (Unhap.) under

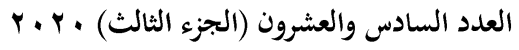

$(160)$

مجلة كلية التربية- جامعة عين شمس 
Mai Anas Lotfy Mohammad Zahra

which discusses miserable feelings (M), insecurity (Insec.) which shows examples of disquiet, and dissatisfaction (Dissat.) which is exemplified by displeasure (Displ.).

\begin{tabular}{|c|c|c|c|c|c|c|}
\hline \multirow{2}{*}{$\begin{array}{c}\text { Post } \\
\#\end{array}$} & \multirow[t]{2}{*}{ Appraising items } & \multirow[t]{2}{*}{ Appraiser } & \multicolumn{3}{|c|}{ Affect } & \multirow[t]{2}{*}{ Appraised } \\
\hline & & & Unhap. & Dissat. & Insec. & \\
\hline 18 & $\begin{array}{l}\text { the grief of this } \\
\text { man's face }\end{array}$ & USA & $\mathrm{M} /$ ins. & & & SM \\
\hline 2 & $\begin{array}{l}\text { Too much sorrow in } \\
\text { their hearts }\end{array}$ & USA & $\mathrm{M} /$ ins. & & & SR \\
\hline 2 & $\begin{array}{l}\text { They just want to } \\
\text { live and protect their } \\
\text { children }\end{array}$ & Germany & & & $\begin{array}{l}\text { Disquiet/ } \\
\text { inv. }\end{array}$ & \\
\hline 19 & $\begin{array}{l}\text { sick of moving in } \\
\text { packs }\end{array}$ & USA & & $\begin{array}{l}\text { Displ./ } \\
\text { ins. }\end{array}$ & & SR \\
\hline 2 & $\begin{array}{l}\text { fleeing death and } \\
\text { destruction }\end{array}$ & Germany & & & $\begin{array}{l}\text { Disquiet/ } \\
\text { ins. }\end{array}$ & SR \\
\hline 18 & how afraid they are & USA & & & $\begin{array}{l}\text { Disquiet/ } \\
\text { ins. }\end{array}$ & SR \\
\hline 2 & $\begin{array}{l}\text { they are refugees } \\
\text { from war }\end{array}$ & USA & & & $\begin{array}{l}\text { Disquiet/ } \\
\text { ins. }\end{array}$ & SR \\
\hline 21 & fleeing terrorists & USA & & & $\begin{array}{l}\text { Disquiet/ } \\
\text { ins. }\end{array}$ & SR \\
\hline 2 & they are drowning & USA & & & $\begin{array}{l}\text { Disquiet/ } \\
\text { ins. }\end{array}$ & SR \\
\hline 8 & $\begin{array}{l}\text { These people need } \\
\text { help }\end{array}$ & USA & & & $\begin{array}{l}\text { Disquiet/ } \\
\text { inv. }\end{array}$ & SR \\
\hline 18 & in dire need of help & USA & & & $\begin{array}{l}\text { Disquiet/ } \\
\text { inv. }\end{array}$ & SR \\
\hline 19 & $\begin{array}{l}\text { all they need is a safe } \\
\text { place for their } \\
\text { families } \\
\text { themselves }\end{array}$ & USA & & & $\begin{array}{l}\text { Disquiet/ } \\
\text { inv. }\end{array}$ & SR \\
\hline 2 & seeking refuge & USA & & & $\begin{array}{l}\text { Disquiet/ } \\
\text { inv. }\end{array}$ & SR \\
\hline 2 & all in deep trauma & Australia & & & $\begin{array}{l}\text { Disquiet/ } \\
\text { inv. }\end{array}$ & $\mathrm{SC}$ \\
\hline 18 & $\begin{array}{l}\text { how traumatized } \\
\text { these people are }\end{array}$ & Hungary & & & $\begin{array}{l}\text { Disquiet/ } \\
\text { inv. }\end{array}$ & SR \\
\hline
\end{tabular}

Table (3) Negative Affective Attitude of Syrian Refugees in the Western Discourse on Facebook

The table shows how the western commentators reflect the negative affective attitude of the Syrian refugees. First, the data remarkably stress the insecurity of the Syrian refugees. It is noteworthy that there are examples of inscribed insecurity. For

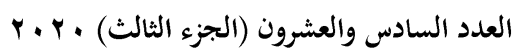

(161)

مجلة كلية التربية- جامعة عين شمس 
The Representation of the Syrian Refugees in the Westerners' Comments on

Facebook Refugee images in 2015: Corpus-based Multimodal Analysis

example, they flee death, destruction, and terrorism. Their children drown and suffer. On the other hand, the examples of the invoked insecurity show that the refugees are searching for a safe haven, peace, protection, and a better life. This is clear in 'They just want to live and protect their children', 'in dire need of help', and 'all they need is a safe place for their families and themselves'. The examples 'all in deep trauma" and "how traumatizes they are' indirectly discuss the refugees' insecurity because of lack of inner peace.

Second, the Syrian refugees are in a miserable condition. This is clear in the use of language, such as 'the grief of this man's face', 'Too much sorrow in their hearts', and 'homeless'. They have lost their homes in the Civil War in Syria. They are also agonized by the bad conditions they encounter on their way to the host countries owing to the bad weather, the drowning of some refugees in the sea, the mistreatment of the border officers in the host countries. On passing all these hardships with his children, a father's face explicitly reflects the grief he feels inside. The refugees are so sad and have lost their way. Third, the commentators also disclose the displeasure of the refugees, in some expressions, like 'sick of moving in packs'. They used to be a civilized nation, but they turn to be packs on boats, fleeing danger and death. They are sick of this reality.

\subsection{The Positive Representation of the Syrian Refugees in the Westerners' discourse}

The positive evaluation towards the Syrian refugees is not remarkable in the data. In addition, the western commentators judge the Syrian children and their mothers more positively than the Syrian men as they are too fragile to bear the destructive consequences of the Civil War in Syria. The following table shows

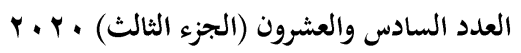

مجلة كلية التربية- جامعة عين شمس 
Mai Anas Lotfy Mohammad Zahra

the commentators' views on the nature and bravery of the Syrian refugees in general and the children and women in particular.

\begin{tabular}{|c|c|c|c|c|c|}
\hline \multirow{3}{*}{$\begin{array}{c}\text { Post } \\
\#\end{array}$} & \multirow{3}{*}{ Appraising items } & \multirow{3}{*}{ Appraiser } & \multirow{2}{*}{\multicolumn{2}{|c|}{\begin{tabular}{|c|} 
Judgement \\
Social esteem
\end{tabular}}} & \multirow{3}{*}{$\begin{array}{l}\text { Apprai } \\
\text { sed }\end{array}$} \\
\hline & & & & & \\
\hline & & & Norm. & Ten. & \\
\hline 17 & $\begin{array}{l}\text { Incredible people for } \\
\text { making such a } \\
\text { journey }\end{array}$ & USA & $\begin{array}{l}+ \text { Norm/ } \\
\text { ins. }\end{array}$ & & SR \\
\hline 2 & $\begin{array}{l}\text { Sweet innocent } \\
\text { children }\end{array}$ & USA & $\begin{array}{l}+ \text { Norm/ } \\
\text { ins. }\end{array}$ & & $\mathrm{SC}$ \\
\hline 2 & Sweet little faces & USA & $\begin{array}{l}+ \text { Norm/ } \\
\text { ins. }\end{array}$ & & $\mathrm{SC}$ \\
\hline 18 & $\begin{array}{l}\text { completely innocent, } \\
\text { completely pure }\end{array}$ & Hungary & $\begin{array}{l}+ \text { Norm/ } \\
\text { ins. }\end{array}$ & & $\mathrm{SC}$ \\
\hline 2 & $\begin{array}{l}\text { Those courageous } \\
\text { Mothers }\end{array}$ & USA & & + Ten/ ins. & SW \\
\hline 7 & $\begin{array}{l}\text { brave and determined } \\
\text { people }\end{array}$ & USA & & + Ten/ ins. & SR \\
\hline
\end{tabular}

Table (4) Positive Judgement of the Syrian Refugees

As shown in the table, the Syrian refugees witness a positive judgement in the Americans' comments. They are described as 'incredible people' for fleeing from war to save their lives and search for a safe place. They are also depicted as 'brave and determined' because they have struggled a lot to survive. Similarly, the comments evaluate children as 'innocent' and 'pure' as they are victimised by the Civil War. They are expected to lead a better life that suits their age and meets their childish needs, but their lives have turned upside down. Finally, Syrian mothers are judged 'courageous' for making the decision of fleeing, leaving behind their dreams and homes in Syria and looking for another place to survive.

\subsection{The Visual Representation of the Syrian Refugees on Facebook}

Post One provides an image of a Syrian family which witnesses $3.3 \mathrm{k}$ likes and one angry face. It also records $1.6 \mathrm{k}$ shares.

r. r. العدد السادس والعشرون (الجزء الثالث)

(163)

مجلة كلية التربية- جامعة عين شمس 
The Representation of the Syrian Refugees in the Westerners' Comments on

Facebook Refugee images in 2015: Corpus-based Multimodal Analysis

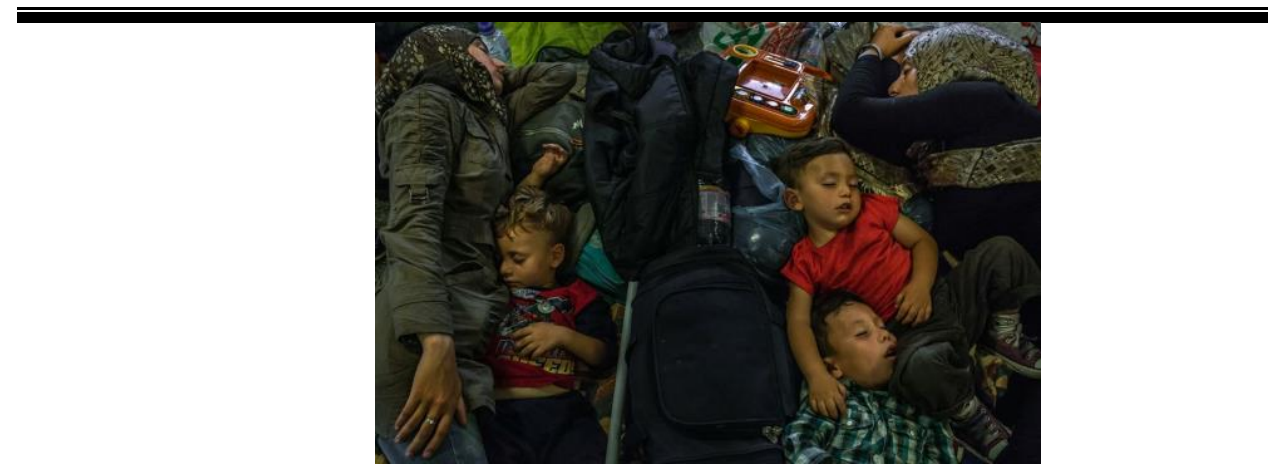

Image (2) a Syrian family lying in the Keleti train station in Budapest (The New York Times, September 3, 2015)

It is an image of five Syrian refugees: two mothers and three boys lying in a train station in Budapest, Hungary, waiting for the approval of the Hungarian authorities to let them pass to Germany. First, the way the mothers are dressed denotes their Islamic background. That is, the two wear a long shirt dress with long sleeves and headscarves. On the left hand, one son is sleeping next to his mother; the close distance between them shows that his mother is expected to be his source of safety, kindness, and support. The son wears a colourful T-shirt and a pair of black trousers. On the right hand, the second mother has got two sons; this is obvious in the intimate distance between them. One of the sons wears a red Tshirt, a pair of black trousers, and black shoes, while his brother puts on a checkered shirt. Their appearance shows that they come from a middle or upper-middle class. They are all sleeping on a kind of blanket, putting a jacket and a black backpack to separate between the two families. There is a bottle of water appearing from the bag, and a toy.

In addition, symbolism also plays a role in this image. To exemplify, the children's toy connotes different meanings. First, it signifies purity and childhood. Second, it means that it is children's stuff which is essential in their daily life. In other words, they deserve to spend their time playing and having fun at this young age.

r. r. العدد السادس والعشرون (الجزء الثالث)

(164)

مجلة كلية التربية- جامعة عين شمس 
Finally, it expresses sad feelings as these kids are too young to bear the burden of refuge, traveling from a place to another. Besides, their setting is the train station in Hungary, so it may be a lifethreatening place. It is also a close shot of a Syrian family, and this signifies that the viewer observes their facial expressions and their exhaustion. The viewer looks down to them, connoting that they are in a bad condition. Therefore, the image is call for helping the Syrian refugees, especially women and kids.

As for Post Two, the following image displays some refugees who have flowed into a Greek camp in Idomeni. The authorities there have built a fence to reduce the flow of refugees.

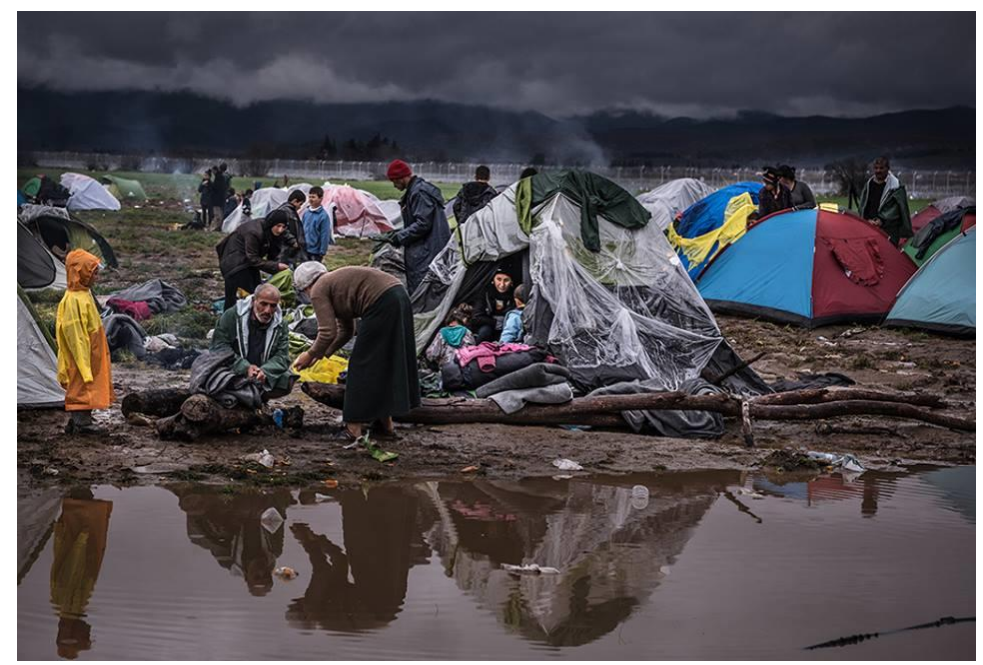

Image (3) Refugees in a Flooded Camp in Idomeni, Greece (The New York Times, March 18, 2015)

The image mirrors a number of Syrian refugees who have arrived on the Greek borders. The surrounding area is in a mess. To demonstrate, the Syrian refugees stay in tents unprepared for living. Parts of the land are covered with grass, while others are muddy. Broken timber covers some of the run-down area. Rubbish is everywhere, and dirty lake is so clear in the foreground. The whole place is invulnerable for the refugees' living and sleeping. In the

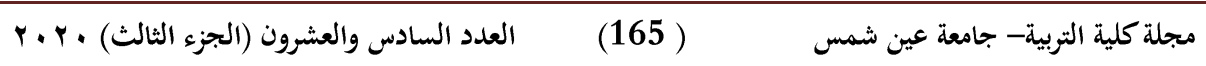


The Representation of the Syrian Refugees in the Westerners' Comments on

Facebook Refugee images in 2015: Corpus-based Multimodal Analysis

background, there is a fence built by the Greek authorities to prevent the refugees from flowing into the country. The weather is cloudy and so cold, and this is obvious in the refugees' heavy clothes. That is, on the left hand, there is a child, putting on a yellow-and-orange coat with a hood on his head. Next to him is an old man who wears a dark green jacket. He is sitting on a piece of timber, in a crosslegged fashion. His posture signifies that he is freezing. He is served some food by a Syrian woman who puts on a beige pullover and a black skirt. She wears a white bonnet on her head, and a black pair of shoes. Behind them is a Syrian lady who wears a long dark brown waterproof coat with black trousers and black head scarf. She is stooping as she is offering help to someone who is not clear in the image. Two children facing each other appear behind her, and both of them put on heavy jackets. Other people appear in the background, but the photographer does not focus on their appearance and gender.

In the middle, a Syrian mother with her daughter and son are staying in their rough tent. The two children put on jackets, while their mother wear black clothes and headscarf. Behind the tent are two Syrian refugee men giving their backs to each other. There is a long dark grey coat and a red ice cap on the closer man's head, whereas the farther one puts on a black jacket, letting the hood off his head. On the right hand, five tents are obvious. Between them, there is a man, probably in his fifties, standing and wearing a heavy jacket with a black top and an ice cap. On his right side, three people are standing; the close distance between them shows that they are a family. A child hardly appears from the blue-and-red tent. Thus, the image is full of details that reflect the bad conditions of the Syrian refugees on the borders.

In addition, there are three participants who face the viewer and consequently construct a relationship between them and the viewer. First, the grey-haired man on the left side of the image looks

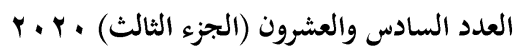

$(166)$

مجلة كلية التربية- جامعة عين شمس 
directly to the viewer, requesting some help and support. He is too fragile to bear the burden of the cold weather, sleep on the mud, and live in the flimsy tents. Second, the mother in the tent, in the middle of the image, faces the camera, but does not look directly to the viewer. Rather, she looks at the food served to the old man on her right hand. This moves the feelings of grief and compassion towards her and her children. She may be hungry and cannot demand some food because she knows that it is so limited. Finally, the standing man on the right side of the image also looks at the viewer; he may ask for spiritual and financial support. He wears shabby clothes. The viewer is also an observer for the rest of the refugees in the image. That is, each man/woman has a role to play in the area: offering help, food, or drink, or do something for him/herself.

Besides, the cultural symbols are salient in this image. To instantiate, the headscarves are cultural-specific; they signify the Islamic culture. Therefore, all the Syrian women in the image are Muslims. The black colour surrounding the mother in the tent (i.e. her black clothes, black headscarf, and the dark atmosphere) symbolizes her agony and danger surrounding them. The foggy weather also signifies the dark future that awaits waiting as they are kept ignored on the Greek borders, and no one can give them hope. Hence, the image emphasizes the feelings of grief, depression, and hopelessness.

Post three presents a Syrian refugee family who has joined a larger group of migrants who are staying on the Hungarian-Serbian borders. 
The Representation of the Syrian Refugees in the Westerners' Comments on

Facebook Refugee images in 2015: Corpus-based Multimodal Analysis

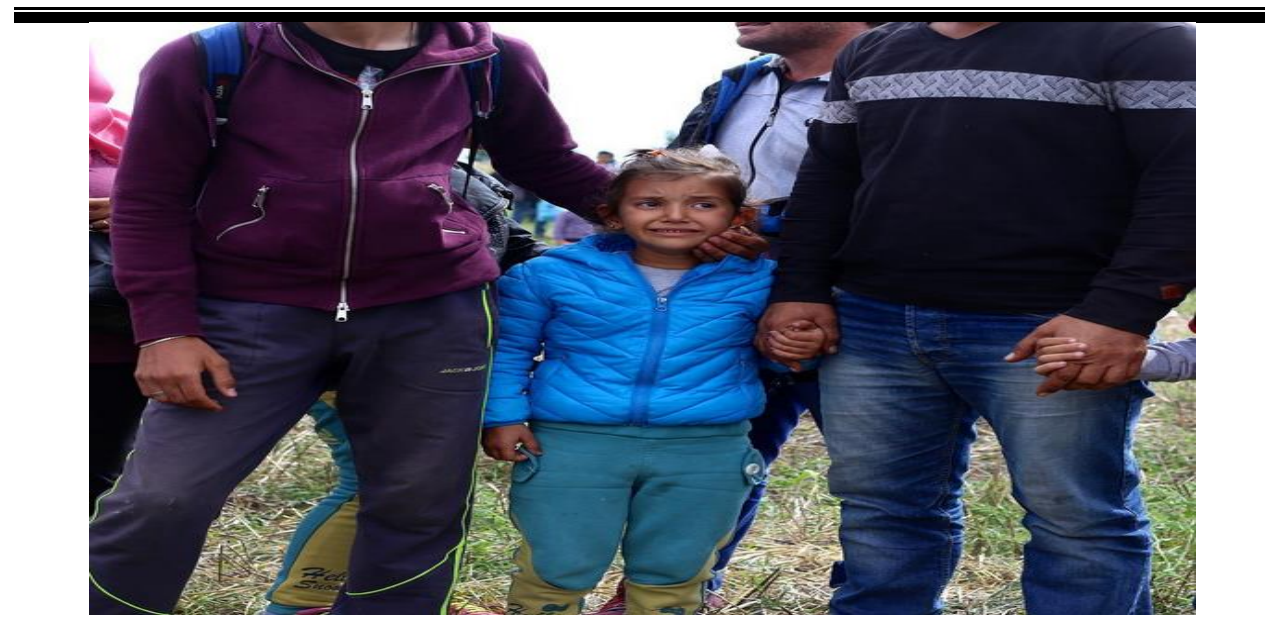

Image (4) A Syrian Girl with her Family Staying on the HungarianSerbian Borders (PBS NewsHour, 9 September, 2015)

The image closely shots a Syrian refugee girl who is probably eight years old. She puts on a blue waterproof jacket under which there is a white top. Her rich heavy trousers and jacket show that she belongs to an upper class family. This exacerbates the situation as she is used to living in a comfortable, luxurious place, but currently her life turns upside down. That is, she has been encountering miserable experiences regarding migration, displacement, and cold weather. This highlights the ideology of threatening the Syrians' identity. That is, the girl and her family have abandoned their home and their civilized way of living to adopt a new life full of difficulties. Although she is holding her father's hand, her looks reflect her terror. She is standing on grass between two men; on her left may be her father, while the right man may be her relative. Her small size compared to the two men shows how young she is to keep such sad emotions inside her innocent heart. It is heartbreaking for the viewer to see her crying eyes, frowning eyebrows, and her lips being stretched in fear.

Similarly, the girl's father on her right hand looks a rich man with his smart looking although his face is not clear in the image. He

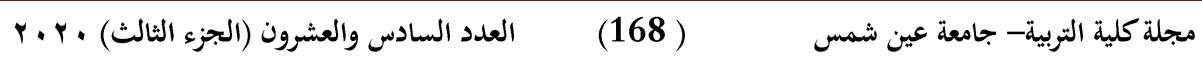


puts on a black pullover with a thick grey line passing through his chest and a pair of dark blue trousers. He is holding his daughter's hand on his right hand and another child on his left hand. Capturing a part of a child's hand signifies the presence of another child, facing the same difficulties. The photographer may also keep the other child off the image intentionally because the girl's facial signs' are more expressive than the other child's. On the other hand, her relative puts on a heavy purple sweater and a pair of dark blue training pants. He puts his left hand around her neck to calm her down. Behind him is a part of another child's leg which is dressed in the same colorful trousers as the girl's. It also reflects that this girl has got another sister, but kept unclear in the image. The mother of these children is discarded in the image for TWO reasons. First, she may be kept hidden intentionally because the photographer finds that the girl's face is enough to grab the world's attention. Second, she may be kept alone in Syria, or she died as a result of the Civil War in Syria. Behind the girl, there is a man who partially appears wearing a shirt on which there is a heavy jacket. He also puts on dark blue trousers. His posture shows that he does not belong to the foreground family. Overall, the image calls the kind-hearted people to provide aids to the Syrian refugee families who share hard times until being settled down in a safe place.

In Post Four, a new image displays a refugee camp situated on a huge area which embraces hundreds of Syrian refugees outside Roszke, Hungary. The image is shared by 73 users and liked by 244 ones. 
The Representation of the Syrian Refugees in the Westerners' Comments on

Facebook Refugee images in 2015: Corpus-based Multimodal Analysis

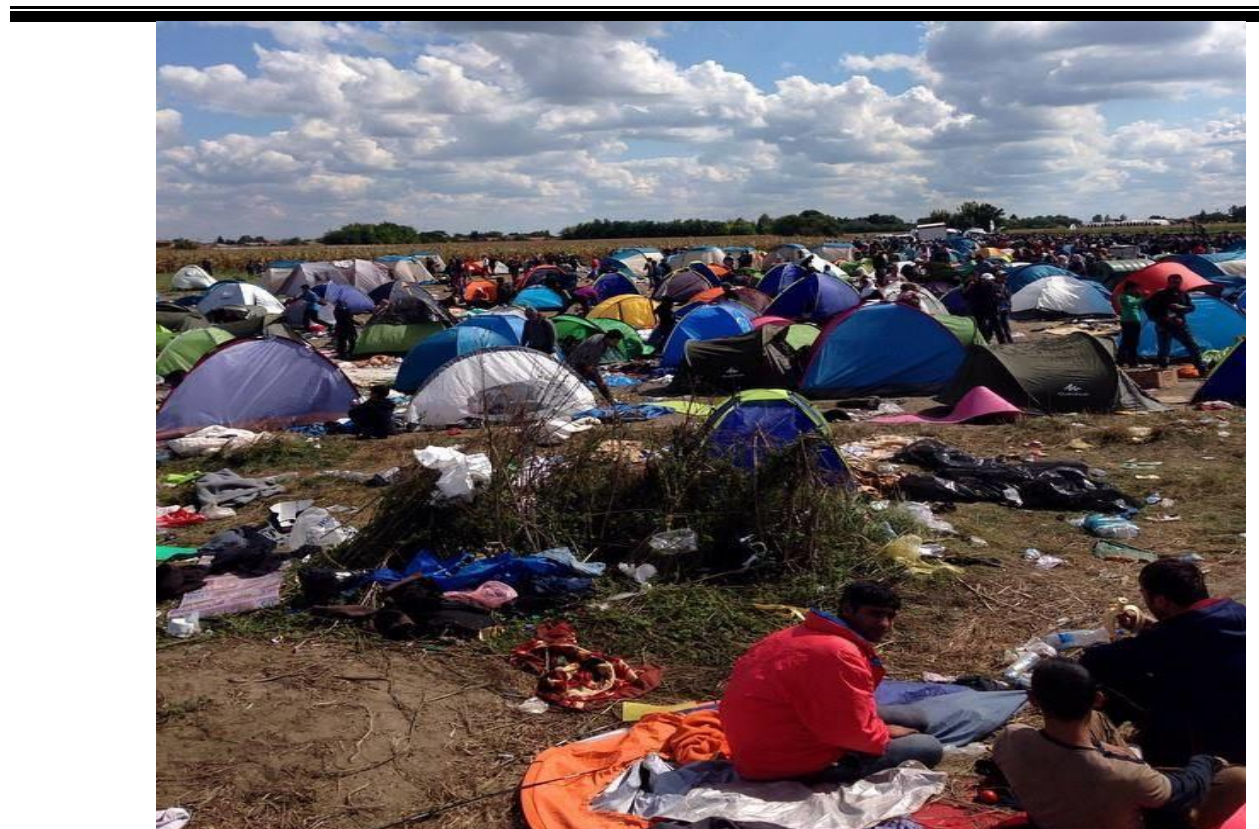

Image (5) Hundreds of Syrian Refugees Settle in a Camp outside of Roszke, Hungary (PBS NewsHour, 8 September, 2015)

The image discusses some iconological elements. First, it is noticeable that there are a lot of tents coving the area. This connotes that a lot of Syrian refugee families have been displaced and stayed in the Hungarian camp until they are agreed to get into and pass to another European country. Second, rubbish is also everywhere; this signifies that such families have been accommodated for several days in the camp. Third, the sky is full of clouds although the sun rises, and the cold weather surrounds the refugees. This shows that besides suffering from the lack of sources of living, they are freezing. This is clear in their heavy clothes. That is, in the foreground, there are three men, sitting on a large piece of fabric covering the ground. The one who is directly looking to the camera puts on an orange waterproof jacket and dark trousers. Next to him is a man with a brown pullover and another one wears a black

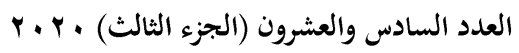

$(\mathbf{1 7 0})$

مجلة كلية التربية- جامعة عين شمس 
jacket. They may be relatives or acquaintances. Their way of clothing shows that they belong to a lower class.

Furthermore, the image draws a relationship between the viewer and the participants. Although the eye contact of the man, looking at the camera, is blurred, the man demands support from the viewers. He urges them to help him find a safe haven, claiming home, a clean place for having some warm beds for comfortably sleeping. On the other hand, the other two men turn their back to the camera as if they hide their spiritual pain. The viewer thinks that they may not want to show their surrender. The whole image represents a place where it is not suitable for humans to live and sleep. Therefore, the image sends a message of taking urgent actions to help these Syrian refugee families get out of their troubles.

The following image is related to Post Five. It is posted by Asylum Seeker Resource Centre (ASRC). It tells a story about Shehd, a Syrian refugee child, who escapes with her family and stays in a camp near Hungary. Shehd loves drawing, but she draws weapons because she sees them everywhere. Her mother states that her daughter gave up drawing as they have left all her crayons and sketches at their home in Syria. This image is liked by $1.4 \mathrm{~K}$ users and shared by 354 users on Facebook. 
The Representation of the Syrian Refugees in the Westerners' Comments on

Facebook Refugee images in 2015: Corpus-based Multimodal Analysis

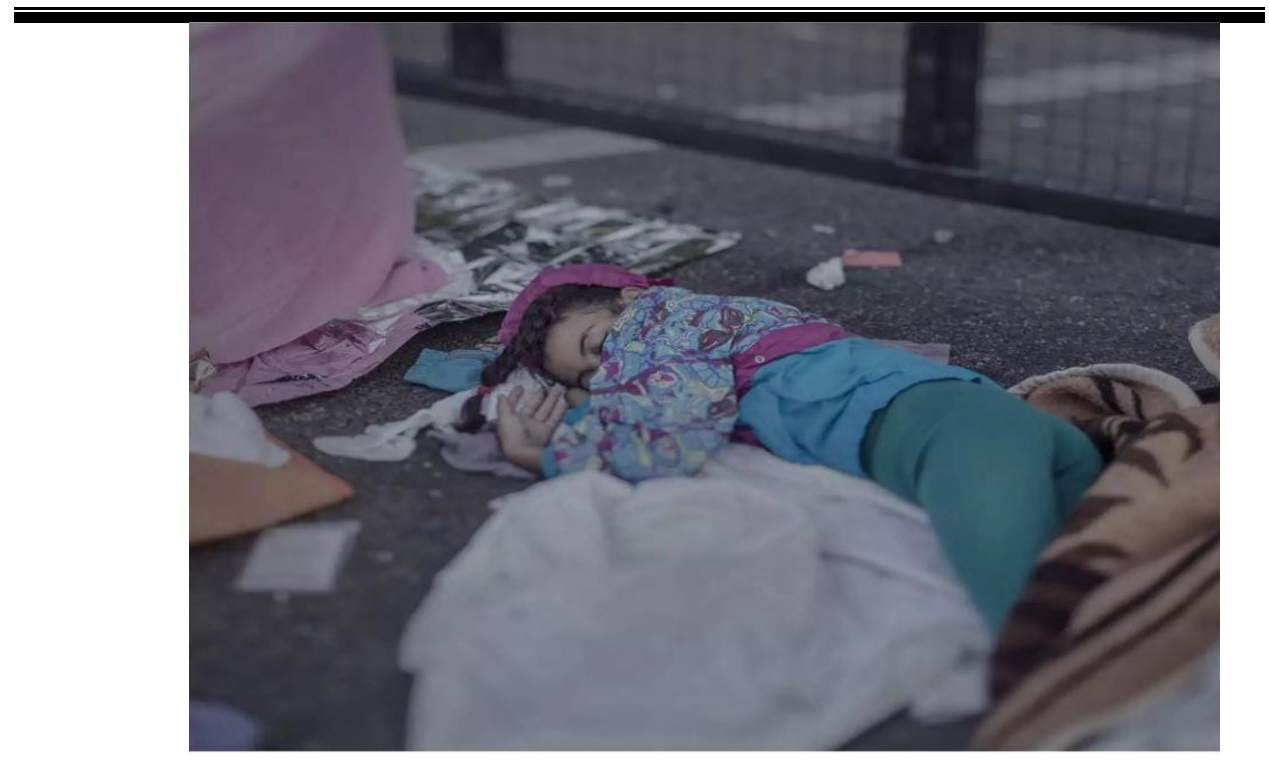

Image (6) Shehd Sleeping in a Camp near the Hungarian Border (Asylum Seeker Resource Centre, 22 November, 2015)

The image captures a seven-year girl, Shehd, in a medium shot. She is sleeping on the ground of a camp near Hungary. She puts on home wear: a long-sleeved colourful shirt and a tight pair of trousers. She looks exhausted although her facial expressions are not fully clear. Her face looks pale. Her body is thin so that she is physically incapable of displacement and fleeing. The bottom part of her body: knees and leg are covered with a blanket. This shows that the weather is mild. Although the surrounding area is faded, it is clear that the area is untidy and dirty. It is also hard for humans to live, sleep, drink, and eat in this area. Via the caption of the image, Shehd is traumatized; she draws only weapons. She has faced a lot of terrible situations in her homeland to the extent that she sees weapons everywhere. She does not enjoy her childhood. Rather, her escape from Syria causes her to have concerns about what will happen in an hour or a day.

r. r. العدد السادس والعشرون (الجزء الثالث)

(172)

مجلة كلية التربية- جامعة عين شمس 
The image brings the viewer to deeply think of her dreams during her sleeping. She may escape from the current events by dreaming of her safe home, playing with her loved people, and drawing a better future. She may sleep to live in her imaginary world and get out of such bad life in the camp. Sleeping on her abdomen signifies that she may hug the ground; she may desire to be buried because death may be better than what she is currently feeling. Like other images, representing the Syrian refugee children in such sad conditions is a call for providing charitable aids for the Syrian refugee families.

Post Six is shared by The Economist; it records $8.4 \mathrm{k}$ likes and $7.3 \mathrm{k}$ shares on Facebook. It is an image of a Syrian refugee man, holding a baby in a life tube. He is swimming towards the shore of the Greek island of Lesbos.

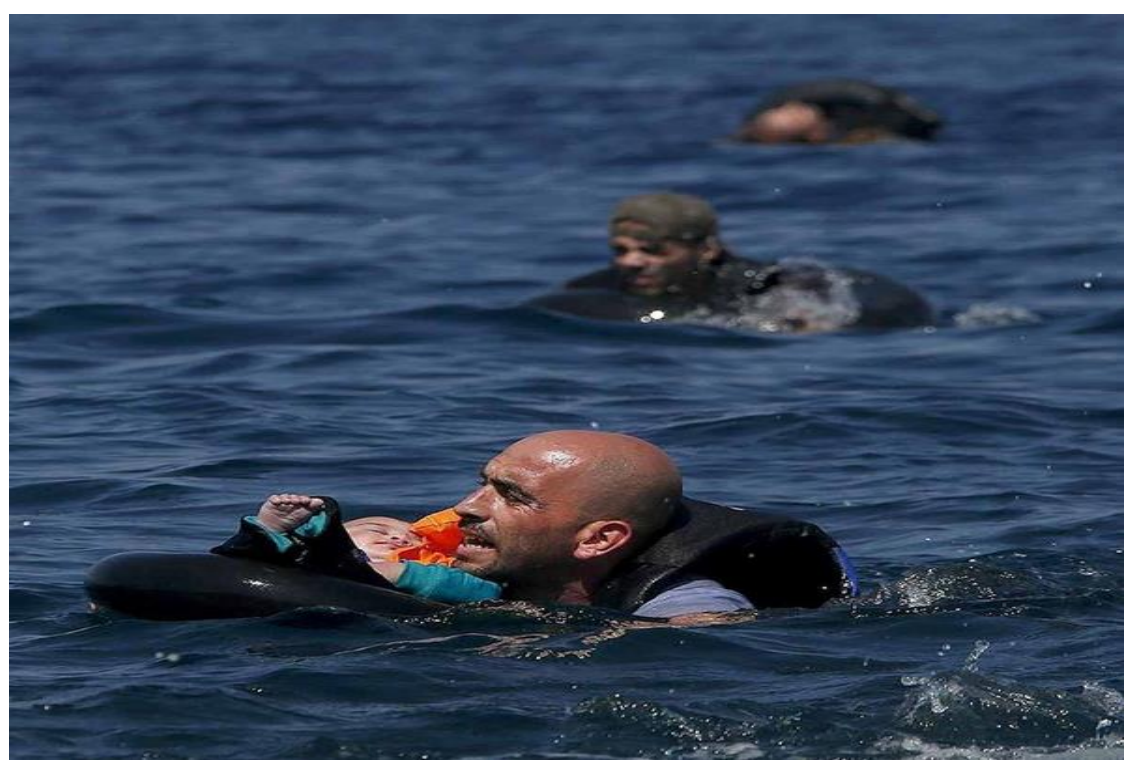

Image (7) A Syrian Refugee Holding a Baby in a Life Tube Swimming towards the Shore near Lesbos (The Economist, 14 September, 2015) 
The Representation of the Syrian Refugees in the Westerners' Comments on

Facebook Refugee images in 2015: Corpus-based Multimodal Analysis

In the foreground, the image captures a Syrian refugee man with a baby in a life tube, swimming towards the shore of Lesbos. The caption does not mention if the baby is still alive. The man puts on a life jacket, struggling in the sea to save the baby's life. The medium shot gives some details of his facial expressions. His frowning eyebrows, stretching lips, and semi-closed eyes reflect feelings of danger, concern, and desperation. After the boat has deflated, it is risky to swim a long distance in the sea with a baby, a weak creature. It is inherent that the sea level is high; it reaches the man's neck. It is also hard for him to breathe because of the water pressure. Therefore, he is worried about himself and his colleagues who are in the same incredible situation. He is also desperate because he does not have any other way, except reaching the Lesbos shore to have first aid procedures for the baby and rescue his own life. As for the weather, it is clear that it is sunny, and this may help them have some warm and rest on the island. On the other hand, the background shows two other refugees swimming in the sea, but they fade away. The closer one to the camera is a man, wearing a cap. This refers to other refugees who are trying to survive.

The side-on medium shot of the man with baby who is lying on the sea surface enables the viewer to align with the man's thoughts and feelings. To illustrate, the viewer is observing the man's pain and suffering, especially because of the absence of the other family members from the image. It is noteworthy that the photographer does not picture the man's clothes since he wants to shed light on the human crisis in which all the Syrian refugees have indulged. Overall, the image clarifies that the Syrian refugee man is caring, supportive, and powerful.

Post Seven is an image of a man who is trying to rescue himself and his son from the tear gas, pepper spray, and water cannons fired by the Hungarian policemen on the borders to disperse

r. r. العدد السادس والعشرون (الجزء الثالث)

مجلة كلية التربية- جامعة عين شمس 
Mai Anas Lotfy Mohammad Zahra

the refugees. The image is liked by $3 \mathrm{~K}$ users and shared by $1.1 \mathrm{~K}$ others on Facebook.

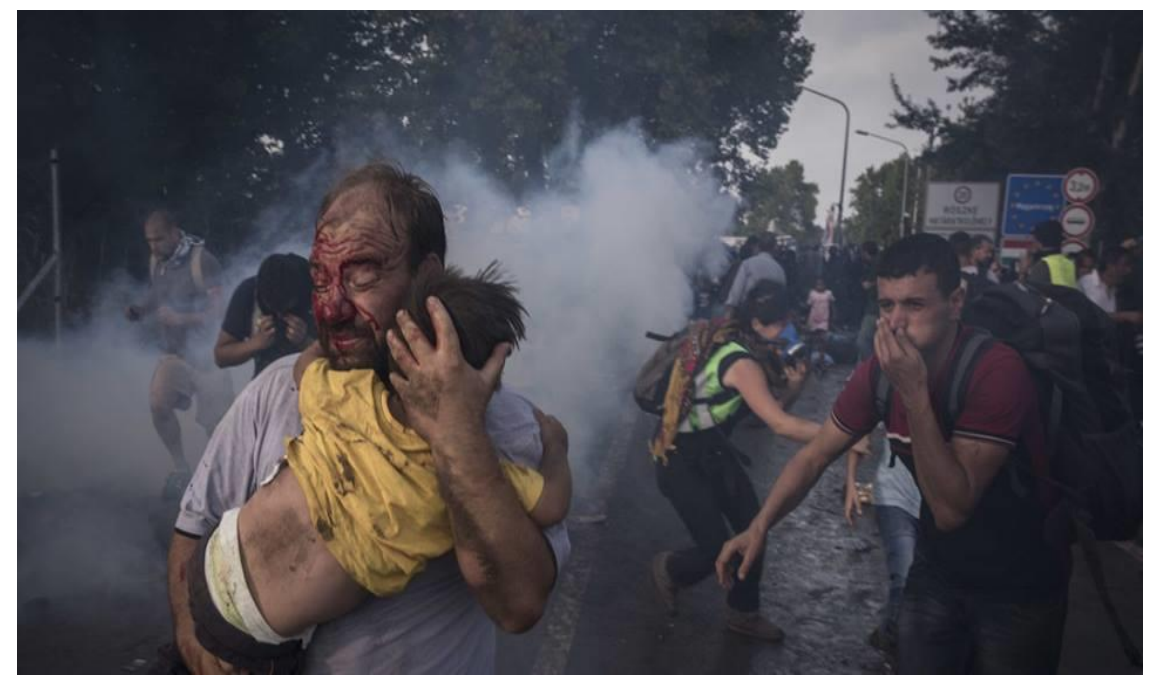

Image (8) A Man Trying to Save his Child on the Hungarian-Serbian Borders (The New York Times, 17 September, 2015)

The image captures a Syrian refugee man, carrying his son to escape from the tear gas and pepper spray produced by the Hungarian officers on the Serbian-Hungarian borders. As he is furrowing his brow, the action ages the man 50 years old. Some blood stains part of the man's face. It seems that his right cheek has a bleeding scar as a result of being hit by a shrapnel during the attack between the Syrian refugees and the Hungarian officers. The man and his son put on shabby clothes; they may belong to a low class in Syria. Their clothes may also appear in a very bad condition owing to the chaotic situation. The boy is clinging to his father who is the main source of power. The father in turn rolls his left arm around the child's right shoulder and head, while his right arm holds the boy's two legs. The father also covers his son's face with his left shoulder. Therefore, the situation reflects some father's attributes: powerful, initiative, caring, and supportive. A part of the boy's back

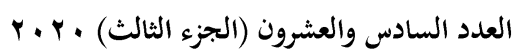

(175)

مجلة كلية التربية- جامعة عين شمس 
The Representation of the Syrian Refugees in the Westerners' Comments on

Facebook Refugee images in 2015: Corpus-based Multimodal Analysis

is uncovered; this unveils that his body is streaked with mud. Probably, the boy has been fallen down and rolled over the ground before his father holds him. The boy may have smelled pepper or gas, so he is unable to continue moving.

The close shot of the man's face lets the viewer share the feelings of agony with the man and his son. The scene makes the viewer personalize this abominable experience. Although the man closes his eyes in order not to see this horrible view, the whole situation sends a message to the viewer. To demonstrate, the viewer may think of taking an action to help the man, his son, and those who are in the same situation get out of such troubles. In addition, the viewer may negatively think of the Hungarian policemen because of their aggressive treatment with the refugees.

On the right side of the image is another man, running, slightly closing his eyes, and clogging his nose with his hands to avoid inhaling the gas sprayed in the air. He wears a dark red-andblack T-shirt and black trousers, holding a big black backpack. The man looks younger than the first one, and his appearance may reflect his middle class. His situation enhances the same idea of the Hungarians' mistreatment and aggression. In the background are a lot of people, among them is a young woman who appears in her phosphorescent vest and black trousers. Her uniform denotes that she is a Hungarian officer or a rescuer. She is putting a face mask to avoid the tear gas and pepper spray. She is holding a boy from his right hand; maybe she wants to rescue his life. Behind her is a group of people and children whose appearance and nationality are not clear. The white smoke occupies a large space in the area. Within the smoke, there is a man in a T-shirt and shorts, escaping from the spray. Another man appears in his black clothes behind the father, burying his face in his T-shirt to avoid the gas and smoke. The viewer is observing the whole situation, wondering why the Syrian women are absent in the image. The photographer also takes a front

r.r. العدد السادس والعشرون (الجزء الثالث)

$(176)$

مجلة كلية التربية- جامعة عين شمس 


\section{Mai Anas Lotfy Mohammad Zahra}

shot of the participants' faces to let the viewer be engaged with their pain and feel their fears.

The following image is related to Post Eight publicized by The New York Times. It is liked by 966 Facebook users and shared by 248 ones. It presents a group of Syrian refugees in a train for Zagreb, the Croatian capital, at Tovarnik Station near the CroatianSerbian borders.

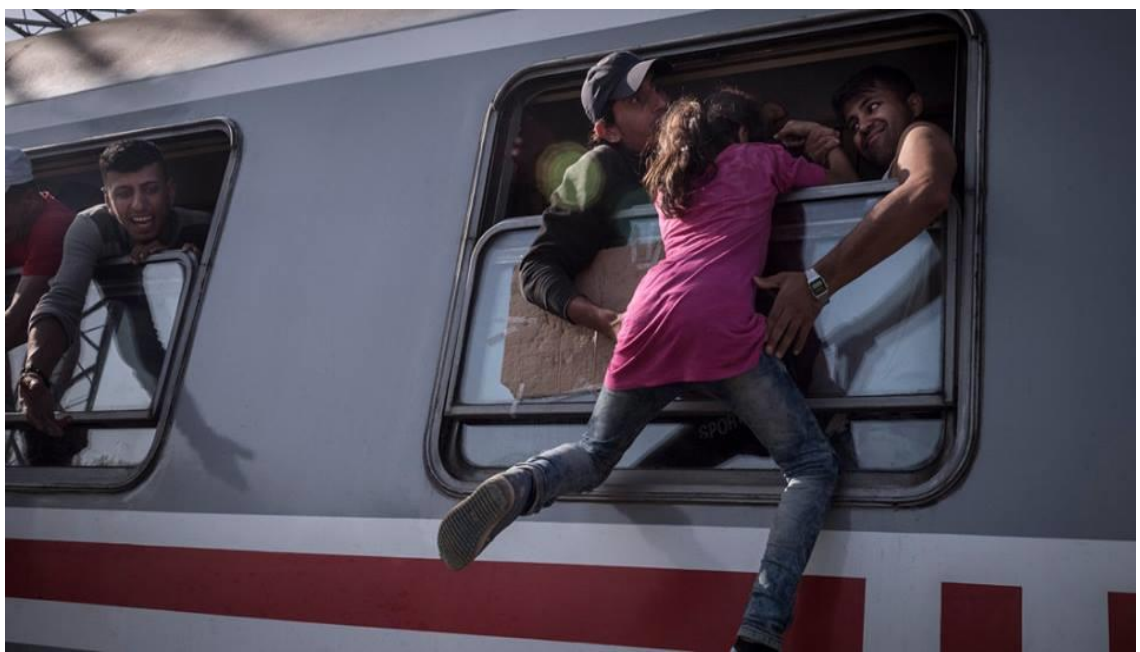

Image (9) Syrian Passengers Struggled to Clamber onto a Train for Zagreb at Tovarnik Station near the Serbian border (The New York Time, 18 September, 2015)

As shown in the image, a train in Croatia is crowded with Syrian refugees among whom two men are trying hard to help a young girl scramble into the train. The caption states that they are traveling to Slovenia where they are rejected to enter. The photographer gets a close shot of two Syrian men pulling an approximately fourteen-year girl from her arm. She wears a long fuchsia T-shirt, blue jeans and shoes. The bright colours of her clothes are contrasted with the pale grey colour of the train and the dark colour of the other people's clothes. This may show that she is still pure and hopeful that the future will be better. Her back is oriented to the viewer, so this discloses her struggle to get into the

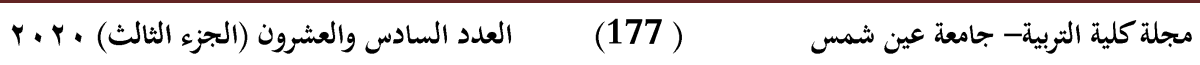


The Representation of the Syrian Refugees in the Westerners' Comments on

Facebook Refugee images in 2015: Corpus-based Multimodal Analysis

train as survival for her life. This clarifies her perspective; she chooses to flee with her people who have the same traditions, culture, and thoughts. Her body is thin, signifying that she is too weak to bear the difficulties of displacement and continuous traveling.

On her right hand, there is a man with heavy hair and light beard. It is clear that his two eyelids are curiously oriented to her. His lips may be stretched, resulting from pulling act or for delivering her a slight smile to motivate her to gather her strength. The viewer is observing the reaction of the man. The man's looks may be interpreted as a support or sexual harassment. In the first interpretation, he may help the young girl because he is a man and is physically stronger than her. On the other hand, the second interpretation may not be effective because it is not the time and place for harassing her. However, the palm of his hand is near her waist that is why the viewer may doubt the man's ethical attitude. On the girl's left hand, there is another man putting on a cap. He is craning from the train window to look at something else although he is helping the girl getting into the train by using his right hand. The side-on of the man keeps the viewer involved in his feelings and intentions. The man may look at another refugee to get him/her up to the train.

Similarly, through the second train window, there are other two Syrian refugee men. The closer one to the camera is stretching his body forward, extending his full arm and hand to help a refugee to clamber into the train. His stretching arm and hand are mirrored on the glass window; this is also a connotation to the viewer. That is, this image demands the viewer to give support to the refugees. The open hand may signify that the refugees need a safe place to have some rest and food. The man is opening his mouth, uttering some encouraging words to encourage that refugee to move quicker. However, the image keeps that one hidden. Next to this man is a part

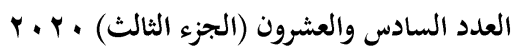

$(178)$

مجلة كلية التربية- جامعة عين شمس 
of another passenger's body appears. Likewise, he is trying hard to support another refugee get into the train. The image tells a story of the Syrian refugees who support each other during crises. They are caring, supportive, and helpful nation.

In Post Nine, the image presents Mohammed, a young man in the United States of America. He has just arrived with other Syrian refugees and dreams of starting his life and staying in America. The image is posted by BBC News, shared by 222 users and liked by $7 \mathrm{~K}$ others.

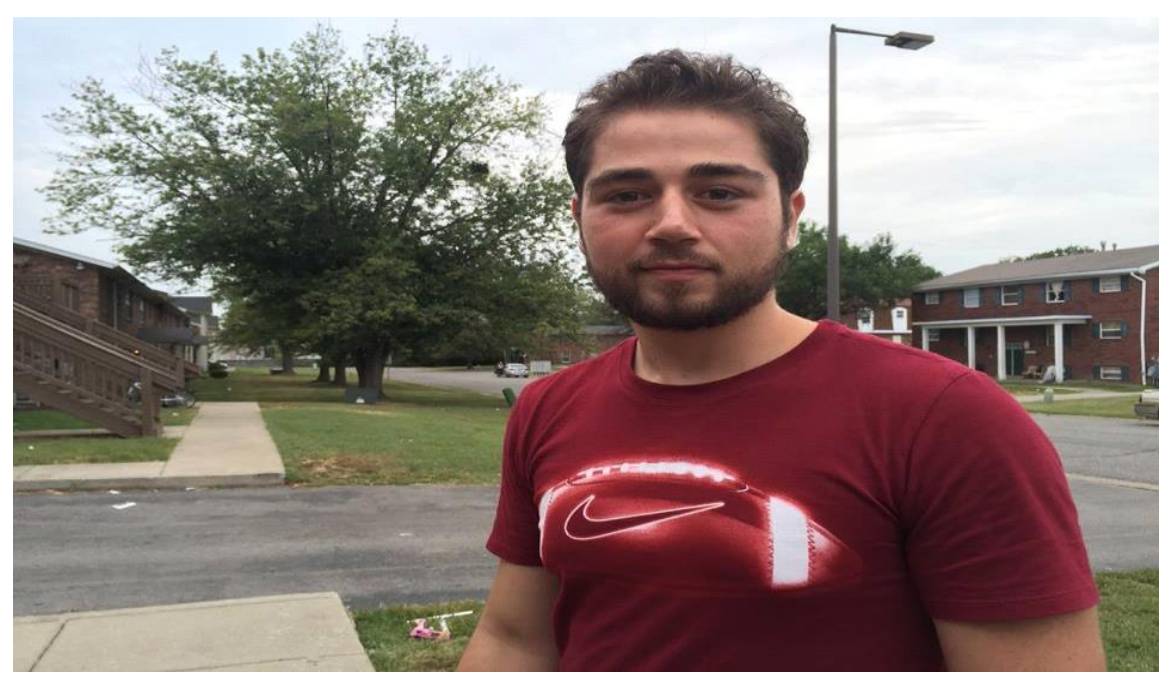

Image (10) Mohamed, One of the Syrian Refugees in America (BBC News, 11 September, 2015)

As shown in the image, Mohammed is a Syrian refugee man who flees Syria to save his life and get a better chance in America. The close shot of his face and upper part of his body highlights some of his attributes. His face is pure and blushed; this connotes that he is well-built and well-fed. It also reveals that he has rested for some time. There is no tiring sign on his face. His neat dark red T-shirt gives him a smart looking and denotes that he belongs to an upper middle class. Although he has definitely encountered a lot of difficulties until he settles in America, he smiles to the viewer. His

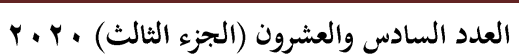

(179)
مجلة كلية التربية- جامعة عين شمس 
The Representation of the Syrian Refugees in the Westerners' Comments on

Facebook Refugee images in 2015: Corpus-based Multimodal Analysis

smile gives a positive energy and assures the viewer that he can start up and find safety. His smile is interpreted as power and hope. The viewer in return smiles to Mohammed and shares his emotions of satisfaction. His posture shows his vision towards the future. To explain, his shoulders are straight and there is no sign of humiliation. His pose rather conveys the meaning that he is ready for adjusting himself to the new lifestyle, culture, and beliefs. Therefore, the image discloses some of Mohammed's characteristics.

In the background, there are some trees, paved streets, and blocks of houses. These contrast with the last scenes Mohammed has witnessed in Syria where trees are buried, streets get broken, and homes are destroyed. The weather is probably great; this is shown in his summer T-shirt. The serenity of the place may be reflected on his soul that's why his attitude is interpreted to be tranquil and encouraging. A plane toy is also seen on the grass behind him; this shows the existence of a child in the area.

Post Ten presents an image of a Syrian refugee child found dead on the Turkish coast. The image has received 496 likes and 278 shares on Facebook.

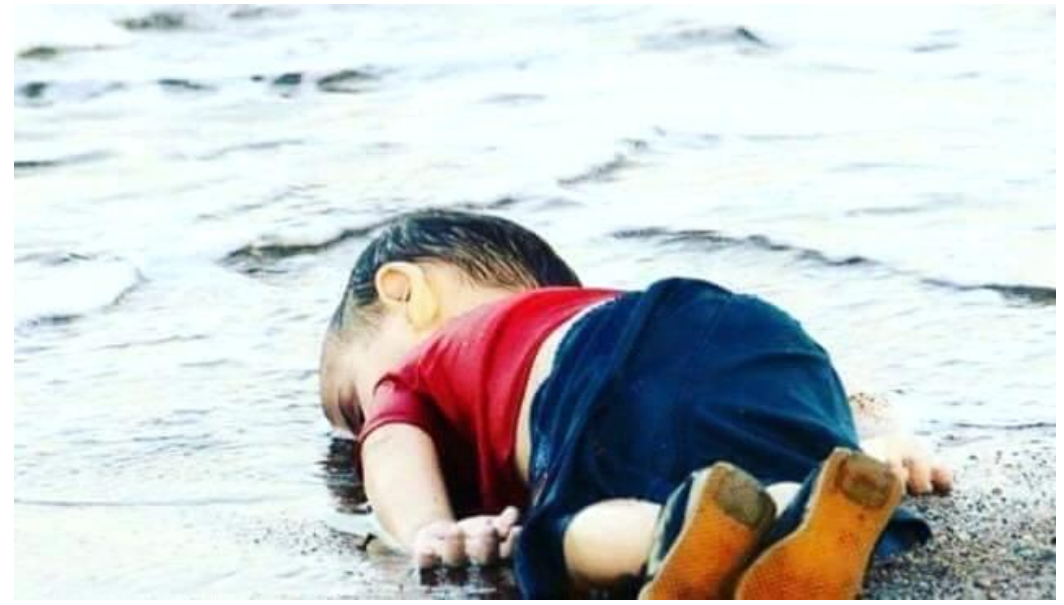

r. r. العدد السادس والعشرون (الجزء الثالث)

(180)

مجلة كلية التربية- جامعة عين شمس 
Image (11) A Syrian Child Found Dead on the Turkish Coast (No2ISIS, 3 September, 2015)

The image shows an approximately three-year child, lying dead by the Turkish coast. It has been the most popular image that overwhelms the social media at this time. His appearance reflects that he belongs to a Syrian middle class. That is, he puts on a red Tshirt, dark blue shorts, and shoes. The child is also kept alone on the coast, suggesting that his family have struggled to save his life, but in vain. He may also have lost his family before having drowned. Overall, the image tells a story of the dangerous journeys that the Syrian refugees have to make.

Moreover, the posture of the child shows his weakness. That is, he is lying on his face with his legs closed and his arms at sides. His face is down, connoting humility and surrender. On looking at the child, the viewer does not look downwards although he is lying on the ground. This is also significant. That is, the way of capturing the image makes the child of the same level as the viewer to show that both of them are humans. The child is not inferior to the viewer. Instead, he is made of flesh and blood and has to be respected especially during his hard times. The close shot side-on of the child also engages the viewer's feelings of inner destruction and complete deterioration. Moreover, the child puts his arms on the two sides, unwillingly opening his palms, which signifies that he demands help. He sends a message for humanity that people should help each other during crises instead of being indifferent. Therefore, the image not only provokes negative emotions, it also sends a message of the necessity of being persevere and caring in order not to lose more lives.

\section{Findings}

\begin{tabular}{|l|c|c|}
\hline \multicolumn{1}{|c|}{ Feature } & N & Percentage \\
\hline ATTITUDE-TYPE & & $\mathrm{N}=277$ \\
\hline AFFECT-TYPE & & $\mathrm{N}=46$ \\
\hline
\end{tabular}

r. r. . العدد السادس والعشرون (الجزء الثالث)

(181)

مجلة كلية التربية- جامعة عين شمس 
The Representation of the Syrian Refugees in the Westerners' Comments on

Facebook Refugee images in 2015: Corpus-based Multimodal Analysis

\begin{tabular}{|c|c|c|}
\hline un/happiness (misery) & 9 & $19.5 \%$ \\
\hline dis/satisfaction (displeasure) & 1 & $2.2 \%$ \\
\hline in/security (disquiet) & 36 & $78.2 \%$ \\
\hline JUDGEMENT-TYPE & \multicolumn{2}{|c|}{$\mathrm{N}=74$} \\
\hline Normality & 17 & $23 \%$ \\
\hline Capacity & 35 & $47.2 \%$ \\
\hline Tenacity & 6 & $8 \%$ \\
\hline Propriety & 16 & $21.6 \%$ \\
\hline APPRECIATION-TYPE & \multicolumn{2}{|c|}{$\mathrm{N}=157$} \\
\hline Reaction (quality) & 129 & $82 \%$ \\
\hline Composition (unbalanced) & 20 & $12.7 \%$ \\
\hline Composition (complex) & 3 & $2 \%$ \\
\hline social-valuation & 5 & $3.2 \%$ \\
\hline ATTITUDE-POLARITY & \multicolumn{2}{|c|}{$\mathrm{N}=277$} \\
\hline positive-attitude & 14 & $5 \%$ \\
\hline negative-attitude & 263 & $95 \%$ \\
\hline EXPLICITNESS & \multicolumn{2}{|c|}{$\mathrm{N}=277$} \\
\hline Inscribed & 263 & $95 \%$ \\
\hline Invoked & 14 & $5 \%$ \\
\hline APPRAISER & \multicolumn{2}{|c|}{$\mathrm{N}=277$} \\
\hline USA & 193 & $69.6 \%$ \\
\hline European countries & 49 & $17.7 \%$ \\
\hline Australia & 30 & $11 \%$ \\
\hline Canada & 4 & $1.4 \%$ \\
\hline
\end{tabular}

r. r. العدد السادس والعشرون (الجزء الثالث)

مجلة كلية التربية- جامعة عين شمس 
Table (4) The Frequency List of the Attitudinal Features on UAM CorpusTool

The table reports the frequency list of the attitudinal features used in the comments on the western commentators. It is clear that the negative evaluation of the Syrian refugees' emotions, behaviour, and conditions is overwhelming (263 units). The comments are also explicit as the inscribed realizations receive 263 units among the three subsystems of attitude. Americans are the most interactive commentators if compared to other westerners: Europeans, Australians, and Canadians. Although almost all the images are captured on the European borders, Americans are the most expressive as they record 193 units out of 277 units. Appreciation is brought to the top on being compared to judgement and affect. It hits 157 items classified into three features with their variables: reaction (quality: 128 units), composition (20 unbalanced units and 4 complex units), and social valuation (5 units). This reflects that the commentators mainly focus on the Syrian refugees' circumstances. That is, their heartbreaking conditions of the camps and their horrible situations during traveling through the sea in flimsy boats provoke feelings of sadness and agony. Their identity is also threatened as they have left their homes and lives destroyed by the Civil War in Syria, seeking a safe place. They leave behind their culture, memories, and jobs without any hope of getting other alternatives. However, some refugees who arrive in Hungary are received by the Hungarian policemen's tear gas and pepper spray. This is described as a disgrace to humanity as each man has the right to live peacefully and comfortably. They are also war refugees so they should be claimed as asylum seekers.

In this regard, judgement is the second common feature among the comments. It has 74 hits divided into capacity (34 units), normality (19), propriety (15 units), and tenacity (6 units). Judgement is the only feature that witnesses positive and negative evaluations. For positive appraisal, they are only 14 hits: 12 hits of normality and 2 hits of tenacity. Children and their mothers are the

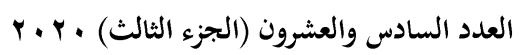

$(183)$

مجلة كلية التربية- جامعة عين شمس 
The Representation of the Syrian Refugees in the Westerners' Comments on

Facebook Refugee images in 2015: Corpus-based Multimodal Analysis

main ones who are positively depicted in the comments. That is, kids are regarded innocent and pure, and mothers are courageous and brave. On the contrary, the Syrian refugee men are negatively described as cowards. This evaluation is attributed to the westerners' fears that the Syrian men may reject the laws in the west, and consequently fight against the regime. The negative assessment is also directed to poor children who are too weak to take on the responsibility of displacement and traveling.

Finally, affect is the least feature used in the data (46 units). The most representative variable is insecurity (34 units). Syrian refugees feel insecure for losing their safe homes, their loved people, and their lives in Syria. They are between the devil and the deep blue sea as the western communities are not better than their homeland. The refugees need help and support to survive themselves and their families.

On the other hand, the visual analysis adds to the characteristics of the Syrian refugees. First, they face the problem of cold weather although the camps are not suitable for living and sleeping. Second, the close/medium shot of the participants enable the viewer to share their feelings and thoughts. Third, the Syrian refugees are caring, helpful, and supportive; they help each other during crises. Fourth, most of the images display women and children as if they are methods for urging the world to take a practical action and provide them with aids. Finally, the setting of the images is either on borders, in camps, train station, in the Mediterranean Sea, or in a host country. This signifies that they are moving continuously, so they are not secure.

\section{Conclusion}

In conclusion, the verbal analysis of attitude under the appraisal framework and the visual analysis of Syrian refugees' images contribute to the study. As for the attitudinal realizations, they clarify how the refugees are depicted on the circumstantial,

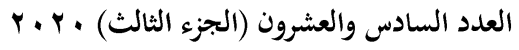

مجلة كلية التربية- جامعة عين شمس 
behavioural, and emotional levels. Their identity is also stained by being traumatized during the Civil War and fleeing to a western host country. In addition, they have to be assimilated with the new western cultures and beliefs. On the contrary, the Syrian refugees occupy the greater space in the images, so this allows the viewer to react with or observe their emotions and thoughts. The analysis of images, based on the multimodal critical discourse analysis, gives more details which do not exist in the comments, such as the refugees' settings, facial expressions, stuff, and actions. 
The Representation of the Syrian Refugees in the Westerners' Comments on

Facebook Refugee images in 2015: Corpus-based Multimodal Analysis

\section{References}

Asylum Seeker Resource Centre (ASRC). (2015). Retrieved November 22, 2015 from:

https://web.facebook.com/Asylum.Seeker.Resource.Centre.ASRC/ photos/p.996999717004841/996999717004841/?type=1\&opaqueC ursor=Abo2QP8td0t9E2yTMMo3v_wvutxEeFm2AKD5s22cHpE1 go4MY3nmckjR-uvAa5jwL9xj-

5xrCRdBegYJC3Mu0OFH9nwouvcMTqCTFFv5R-

74NUNLvAKoF8mcfiWPWQEzqwf61i5xB8nf2yKiaWuMJPM4

DZFFzsttoMCOV8Tr9r-SBhdSO1sRqmLdeKUHLub2sDsqducDU2-

LliYmOFlwXffRzXnAwfq3PfZ23LHz9LKO89C0K0A7jRf1yzf3b dut4L32rt2PERQP-

qwSasDyltemhYiRCuBTJ3yyjr5d7VbN9h029I6qOIHF7KZKCAn Wr0rk1abOth0LOnuwPYUfqoaTbE48RwbE38GXQ0NKvUrrajys 0ylvhA0qET2Ftepf2V4EahfwliEt-

0iRslFqekxDgEC8I1u0HoEHCpCve tDNP4OM8FtTLJK0fJrmEj ndBe1co4BnhYN7bddQrMkKC6A8z01A4bz9neFdJYbtYfXT78ja CxUacsbPSVe5p3e98BJ11lKUBOUVJcj78kZzSh5-

huDVkkX054uHogY3IRcBP8bhRRnBaeJMq4snCohDM\&theater

BBC News. (2015). Retrieved September 11, 2015 from:

https://web.facebook.com/bbcnews/photos/basw.AbqwELSVsxL6 VIfD9wyhWxuvsWet8XG6fgKaLO0pAXXILu_gwpSqvh2nQtBq 0QCNQKymhS9XNo-

bm51UNKQlmW 10DMXe9jaV7ZS09ZZMNVWbSMhty0z6tPQ TsAuEqyKg-

K49WbMDF10dEObZgS9N5mlBUg8y3yDUZRdFMhvWT9Mkm QbylDcFD_NjhUT_ZFFl2dL79TUerUytzidqzwYXXuQNXIbws W3V7D0nnXkxlB0kJTBRhPNfw_cCCg3gImUDwoiyBBo2dJrF Md1ckgeoKjnrU6F3ytjlUI5N5xhd2dVL4MrbICe6OJx2EwS4tXpPI0kTlt5EMva95n8FW0_-

J0NlIbiBzOu8SyremPxo59Uw.10153087123937217/1015308712 3937217/?type=1\&opaqueCursor=Aboa2bNtLCk6J21aSyhiwXnu a9qD9Z72LJ9zjaX_h7tQiHC-

r.r. العدد السادس والعشرون (الجزء الثالث)

(186)

مجلة كلية التربية- جامعة عين شمس 
Mai Anas Lotfy Mohammad Zahra

TNRDzuhWYALwCtDL2o7nQk8X XlBpWanVVR4v5K1Yfw7Z GMMsTHgdJBwOZedbVTcFCX94-

vAtY NqHX7SUsIAKBTr4CcpEDJjmseIt1nRK6rD81d9TyFXVk KQ5UmG2JLECmKDwXWDZrZaVhzXjlHeO96Ao4XqAxnZs3

HVAsioMVcsUhzL9i336d68AmGWwfYIKAmgviHc4WlyFexPK 7fW4cAFUbT 3cb8HKZYhiyzykaECj2zUYdpDtWFF39I4c9Ht0OrNIt2C75n8jUOxWi7Umt2ZqxVxnbqHBgmk39WdRtFn hxvJgNE7L2y6WIuhvJgm9fkXwHXGcSrHijom_XIsgY8RGp68w dVlJjtt45jNxvbTGcHBC7HNj5YsKcbnVHwOEb8JT6e2X880geK oQv0cp_NbWozqXiRm-W0iPInrxhAdimqsyE8tOjqj-

L79eRUasP73Bid1z90vdifab-

RXUHgCbG95aaa1O2W1ytEiUAuoVJS5ZTI1G8YLENhOXKgK blWSgSR6W24WS8enfgcTcihFNc7YYCgySOusp7yktLmR7j1GL tlI6sBaPqDMBrmOJMaLoZyR4jqwDvgc\&theater

El Melligy, F.A.(2013). Coverage of the Egyptian Revolution (2011) in

Aljazeera English and the BBC Online Websites: An Appraisal Theory

Approach. (master's thesis)

Gries, Stephan Th. (2009). Quantitative Corpus Linguistic with R: A Practical

Introduction. New York: Routledge

Halliday, M.A.K.\& Mattiessen,C. M.I.M. (2004). An Introduction to

Functional Grammar. London: Edward Arnold

Hansen, A., \& Machin, D. (2008). Visually Branding the Environment:

Climate Change as a Marketing Opportunity. (pp.777-794).

Van Leeuwen, T. (2005). Introducing Social Semiotics. London \& New York:

Routledge

Lemke, J. (2002). Travels in Hypermodality: Visual Communication. NY: City

University of New York

Machin, D. \& Mayr, A. (2012). How to Do Critical Discourse Analysis: A Multimodal Introduction. Los Angeles: SAGE

Martin, J.R. \& Rose, D. (2007). Working with Discourse: Meaning beyond the

Clause ( $2^{\text {nd }}$ ed.). London: Continuum

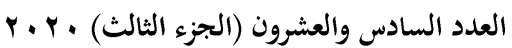

(187)

مجلة كلية التربية- جامعة عين شمس 
The Representation of the Syrian Refugees in the Westerners' Comments on

Facebook Refugee images in 2015: Corpus-based Multimodal Analysis

Martin, J.R. \& White, P.R.R. (2005). The Language of Evaluation: Appraisal

in English. Macmillan: Palgrave

McEnry, T. \& Wilson, A. (1996). Corpus Linguistics. Edinburgh: Edinburgh

University Press

No2ISIS. (2015). Retrieved September 3, 2015 from:

https://www.facebook.com/No2ISISofficial/photos/a.1427248367

554641/1627829390829870/?type=3\&theater

Oyserman, D., Elmore, K. \& Smith, G. (2012). Handbook of Self and Identity.

Leary, M.R. (Eds.) \& Tangney, J.P. (Eds.). $2^{\text {nd }}$ Edition. The Guilford Press: New York.

PBS NewsHour. (2015) Retrieved September 8, 2015 from: https://web.facebook.com/newshour/photos/p.1015361935357867 5/10153619353578675/?type=1\&opaqueCursor=AboVtPoynFTw CNWnuh282OGCm6T2G4AZu125_e0yxXaAOvMxaZspm_yqAE zuKpnF14sFtyObvQFRWswmKbLgFDLhA5yD6sg8rtT1C8icTnC 1OFx2RmPt7IWZIZhpS1tnwgsOJ67kKVBEjLMhTosOUnIpfy3V Oeynyfa_q_tntDhQlBHgUfhZk8Rnk654lVohz9VdLEwnGOVIa2 7_6jto5ivr7dw92Js0kf4iPLOO5yRb24Llpt2Ty-

LWoRI2veA17LqaAQSX-

gbANPe6gXKm9 34rekrTGygaq100Eun4bO6lc1EFzQdCk6cJhvI IGIRkHszYgR39Ra8UsJ-feUtLcmkdg8Qpdot9yABAWm6g9VV_dTU3n0WRcXs3xADWLmAEMih0ejCvJywzuYv2B_RhYCsc71JfzjAs _y7I75u7c2_MVyU80GpyiyA3_OGUOofEwGtzTtBAJChwb9D WY2OkVDbQj7Z0FV7pC_ggmLmyJ74EjXKM1XLfJtvVnbMvO 6Jw\&theater

PBS NewsHour. (2015). Retrieved September 9, 2015 from: https://web.facebook.com/newshour/photos/p.1015362138548367 5/10153621385483675/?type $=1 \&$ opaqueCursor $=$ Abptt $4 \mathrm{vfO} 7 \mathrm{wFc}$ ZUwW4D8-

r. r. العدد السادس والعشرون (الجزء الثالث)

(188)

مجلة كلية التربية- جامعة عين شمس 
Mai Anas Lotfy Mohammad Zahra

VOP4TCGLR2JalKTA3OJXmT4djv3GcpJ2nhlB3GVQUXaNYu AWvMqYIjwWNwUMLkN2nurHIvzofPqnkFpFWT4cl1rSFVPU6dSchvr_giaGNimfKbHuZ4rZKmWgXHx Zxle7Pzu146gjWSZjZ48nB4UjNxCeWJGOlBwJ-Ald9TPN84q5rNVRvAxOnUMQ21iSWoccnWKMCE3UzoCrX_0TOn9 UBBIiW0OLDwegyDTdvJg0jn0qV18carQCZEDgb3TE36d8Mo FtrfVt8E2POMR8GWunCrjdyqXAHgFikDZKgJi3wugC7NlR33IiDdLoT754j4IAC7SiWR8va87nPHSpzcpWRYX3PDsR4W mAOzVVVfBVMyUI3at7jir6YZ5fqnpNF-

0AJlvoUnQfgt5PfLYdiUIn3rH5Ad0YSDsKp29byjOd5NuGMTP

5kR-jFzryUshxHb5jkSe7FVgTBLLn391qoKvGEP8qEUpBq05OaSgRc-

3m5KuXYtRbr_s2yhAGVYm9oQGIUEgYJE7AfmI00f8xuCHw \&theater

Syria: The Story of the Conflict (2016). Retrieved March 11, 2016, from http://www.bbc.com/news/world-middle-east-26116868

Tupala, M. (2019). Applying Quantitative Appraisal Analysis to the Study of

Institutional Discourse: the Case of EU Migration Documents. Finland:

University of Turku

The Economist. (2015). Retrieved September 14, 2015 from:

https://web.facebook.com/TheEconomist/photos/basw.AbqVfCtx

MWooPB7HB6if2QSWGwawy2cHQp53jeeZtVEInt0oCRMxGg3S-

Ikr0I76hWEebvdFJVScL7BbjqkUVnIpQw2vxarDF7BUSgBZovT iyjAXgwFYfOi0NzUjE3r3hX7R6Jt7P39wNVuBYP2nU3OrfmgaI sSkgemLB6QxB3NMA.10153615768769060.1015368795777906 $\underline{0.10153582387544060 .10153606136759060 .10153617712799060}$ .10153714901339060 .10153308166204060 .10153592027029060 . 10153568475159060/10153617712799060/?type=1\&opaqueCurso r=AbqYWV9oPv9QSTyzUu08lgtxhzbpQb1cblG_JtuTjqw6TvtSD RekysyD66Kw4Ye jTsssLyfOcEHgHyGxSPC1BY56fuKIkXcRe ploEeQyQwBBI5uGkl5h76TBJu-

6wJO5aajZvuFGW Vo064UQNHbIalpV7Lz7aOfFwgwhj34Qb W66oEVBNQWwCAs0fHzyqhhIhMB7PCu5xaiB0GxH4XpcMV

العدد السادس والعشرون (الجزء الثالث) •r.r

(189)

مجلة كلية التربية- جامعة عين شمس 
The Representation of the Syrian Refugees in the Westerners' Comments on

Facebook Refugee images in 2015: Corpus-based Multimodal Analysis

TV9W10D-

v2SfXiXTeYZboY4bRd6Egsh9M3AkNWBawPEtfaOoLAL_qtZx tyMEpF1Dns1f8KsNP7RjDET8b1JU3YO098ohxQTOsnYQqd621 67a9Li6XTU3D0HxXkOxZxbgOM_kQuyM51OrNrhtKgqM81Nrn vsQS0tWauYMJqMuhk6upAx4bR gtcpNcEoZ-

CRxOwy6xlY13VsGI9bHjST18tIwkCqVWSF8BoHRZ6NwuzVS JHKdlzmokGv1FMVqToA-You6ML-

IPAHWqhARBz7EywezF4adq_165fNaaF8C63khzLgrrb318fGk0is H2cypkoGjsTJtuUGWB-

paG_rZxQbgRN7d2g_4NsESfnxeoo\&theater

The New York Times (2015). Retrieved March 18 from:

https://scontent-hbe1-1.xx.fbcdn.net/v/t31.0-

8/856964_10150773514324999_6747757755230340046_o.jpg?_n c_cat $=103 \& \_n c \_s i d=2 d 5 d 41 \& \_n c \_o h c=U r k q u g l w 71 E A X 9 j w y f p$ \&_nc_ht=scontent-hbe1-

1.xx\&oh=3e4a4e5df398213d1d59aea7ec01d267\&oe=5E968C0A

The New York Times. (2015). Retrieved September 3, 2015 from:

https://web.facebook.com/nytimes/photos/p.10150657827654999/ $\underline{10150657827654999 / ? \text { type }=1 \& \text { opaqueCursor }=\text { AbpAxVoZ4KTdF }}$ $\mathrm{gb}-$

nze9oSxDBhdp5BoreN3aMjGAPbM6E6fYvlBFp9wmcshvDCVV Iw4iKYQe-oAKm9nGGB0SnmGy7sqLnHcXTPYKiwb1iDeVvlC4-y3oKliss7xvkR0eRwHzR4JxC3TTOii18SP1CrcypbeJL4hMBgBvRv3alPDSHuToA6KZEdzQwQYgAUwOw1bC $\mathrm{C} 2 \mathrm{R}-$

Q1ggvomL0BO3kiiJrHQsj4t7k9KhiWFnDoaJucR8VzpyiOrXrFL CzQwRwT_Gluv38fbitNCJ9S71ozZOS3nYa_NbCkQa_GFv_wevcBgf8-

z0TYtJbqu9Jyj21aPU5ux_Y6VRckd3SIsseIzIDMO7nB1Y0KbtA Br6n5BdNCwRJUto6MVMQQy1NUxcVmik-bs26ZCol-FYyBmMeZgZKgCDaztNGdq3VAGU2uVmHzrh5sVY3sXgFSUP23ah OCYi7CaHOsOAXyTWpzQw8_JhVwQFPJnRB4T8t7xEZK7rgm vzFSFA9rKny7BiK6M\&theater

The New York Times. (2015). Retrieved September 17, 2015 from:

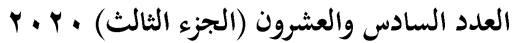

مجلة كلية التربية- جامعة عين شمس 
Mai Anas Lotfy Mohammad Zahra

https://web.facebook.com/nytimes/photos/p.10150666773309999/ $\underline{10150666773309999 / \text { type }=1 \text { \&opaqueCursor=AbqjIWRtlyj6_tLr }}$ 9OWZbvPetvzcbJwGgjpwyvT0vQRvz6UB0wtVK7wi7mq7Bhzp1 AQTfNs7Ye4n_Y4XazQGjcgBD3_TZFeSt5MRbWtcY37sHDkRjL_R9HTWlrxgw71isjVbpB8 MfNeQFmuA9nrudHpwLAHdftfLbmW9icWw1m_oXEUalC90F1 wkWx6AxcPAS1F1en0Vc01e06GF8b-_w-

CFMf7akNSQmXrPxDQK-

XSMvVM2SM3TxmRmRQ3t7YoZ1FIxoP9fphYicn2nN9XZWg wVxHoa957z6PEkOZANu1gqrkWVdTQHXfjEVygBZ 6R6nMfqeD97yIMy9LjosHBLDzJ WXaTrcGpPZ4mHMplNjSevu0Y00yF2_Be5F9k8iYjgQZC8v0Oc caotriyoouQaYN5KOSHnrdUUMLpDbFCFyTidK5JyIe_bNmNwj R9keQPAw1EYexF_Zc8BZoDIqUXGQ\&theater

The New York Times. (2015). Retrieved September 18, 2015 from: https://web.facebook.com/nytimes/photos/p.10150667420799999/ 10150667420799999/?type $=1$ \&opaqueCursor=AbretJmVhrN0i58 FVhkk_KPgroU_ewxco70ImIW3OhAhkaxmdeepGXxNiAdIkaFCnAg9RINg6qE7bDYuW Fqsot9qForJ7j9wfMnnxsgcmLYgyy1H9gNqVoeQTZ943cistsW3Ask6Gz2O9gsXWMoPe6I4kquTUfFCg3dbutx1CHndmxkp9_9Q9F 2xvZTshkhZ9dAiQASITmXaKGZrfdcEJ3hdE-EaHCXF1-W+sU2N2IRYfUa776lbiIeicb7R5MeoGTutASCT8wobcnVEINd0U m5buJR1ah0-j9sVRNY8-

yiRLifxt9Pt2Gqt0AHRwBoLU5S7CqoviCmgPfpSTeNH2YQllF5i 9_oed920TY4Ih9jawMmUMVJESXmfJlkd8pKxIR1m6ovS5fdgIk 49K0ZUcdto9AykpSWnqWu5jfg_uwj_0ptGtqxf2HnJwzrGWXZZ NYRTEwBicgHT4Q5UfTVNU\&theater

UAM CorpusTool, (n.d). UAM CorpusTool Software (version 3.0). Retrieved

May 2012 from: http://www.corpustoo.com/Documentation/UAM CorpusToolTutorial3.0.pdf

van Dijk, T. A.(1998). Ideology: A Multidisciplinary Approach. London: SAGE

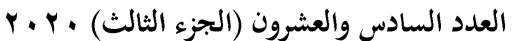

مجلة كلية التربية- جامعة عين شمس 
The Representation of the Syrian Refugees in the Westerners' Comments on

Facebook Refugee images in 2015: Corpus-based Multimodal Analysis

van Dijk, T.A. (2000). Ideology and Discourse: A Multidisciplinary

Introduction. Barcelona: Pompeu Fabra University

van Dijk, T.A. (2005). Critical Discourse Analysis. In Schiffrin, D., Tannen,

D. \& Hamilton, H.E. (Eds.). The Handbook of Discourse Analysis. Retrieved from:

https://onlinelibrary.wiley.com/doi/book/10.1002/9780470753460

العدد السادس والعشرون (الجزء الثالث) •r.r.

مجلة كلية التربية- جامعة عين شمس 